\title{
ESTIMATIVA DA RESISTENNCIA DE DOSSEL (rc) DA GRAMA COM O USO DA TERMOMETRIA AO INFRAVERMELHO
}

\author{
LUÍS FERNANDO DE SOUZA MAGNO CAMPECHE \\ Engenheiro Agrônomo
}

Orientador: Prof. Dr. MARCOS VINÍCIUS FOLEGATTI

Dissertação apresentado à Escola
Superior de Agricultura "Luiz de
Queiroz", Universidade de São
Paulo, para obtenção do título de
Mestre em Agronomia, Área de
Concentração: Irrigação e Drenagem.

P I R A C I C A B A

Estado de São Paulo - Brasil

Dezembro - 1997 
Dados Internacionais de Catalogação na Publicação (CIP) DIVISÃO DE BIBLIOTECA E DOCUMENTAÇÃO - Campus "Luiz de Queiroz"/USP

\section{Campeche, Luis Fernando de Souza Magno}

Estimativa da resistência de dossel $(r c)$ da grama com o uso da termometria do infravermelho / Luis Fernando de Souza Magno Campeche. - Piracicaba, 1998.

52 p. : il.

Dissertação (mestrado) - Escola Superior de Agricultura Luiz de Queiroz, 1997. Bibliografia.

1. Dossel (resistência) 2. Equação de Penman-Monteith 3. Evapotranspiração 4. Grama-batatais 5. Modelo matemático 6. Termometria I. Titulo 


\title{
ESTIMATIVA DA RESISTÊNCIA DE DOSSEL (re) DA GRAMA COM O USO DA TERMOMETRIA AO INFRAVERMELHO
}

\author{
LUÍS FERNANDO DE SOUZA MAGNO CAMPECHE
}

Aprovada em: 23.01 .98

Comissão julgadora:

Prof. Dr. Marcos Vinícius Folegatti ESALQ/USP

Prof. Dr. Nilson Augusto Villa Nova ESALQ/USP

Prof. Dr. Clóvis Alberto Volpi FCAV/UNESP

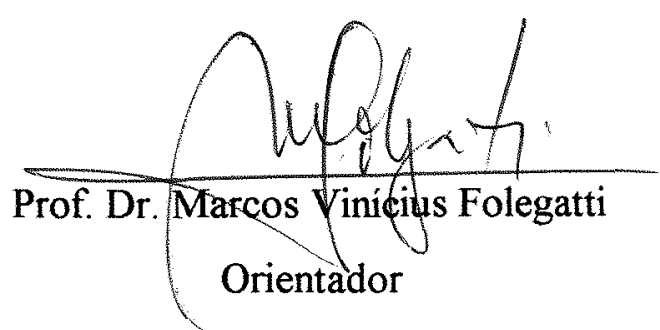


Aos meus pais,

Fernando e Nola

Dedico

à minha irmã,

Aloma

Ofereço 


\section{AGRADECIMENTOS}

Ao Departamento de Engenharia Rural, pela oportunidade de realização do curso.

Ao Prof. Dr. Marcos Vinícius Folegatti, pela admiração, confiança e pela orientação durante a execução deste trabalho.

Ao Conselho Nacional de Desenvolvimento Cientifico e Tecnológico (CNPq), pela bolsa de estudo concedida.

Aos professores do Departamento de Engenharia Rural e de Física pelos ensinamentos prestados.

Ao Prof. Dr. Nilson Augusto Villa Nova, admiração, incentivo e idéias na análise dos dados.

Ao Prof. Dr. Clóvis Alberto Volpi, pelas sugestões apresentadas.

Aos colegas do curso, pela convivência, companheirismo e amizade.

Aos colegas Chico e Sérgio, em especial, pela grande amizade, convivência, colaboração e apoio nos momentos mais difíceis.

Aos funcionários do Departamento de Engenharia Rural, César, Zezinho, Hélio e Gilmar pela ajuda e colaboração.

A todas as pessoas que ajudaram direta ou indiretamente na realização deste trabalho. 


\section{SUMÁRIO}

LISTA DE FIGURAS vii

LISTA DE TABELA ix

RESUMO

SUMMARY xiii

1 INTRODUÇÃO 1

2 REVISÃO DE LITERATURA 3

2.1 Evapotranspiração 3

2.2 Métodos de medidas e estimativas de evapotranspiração 5

2.2.1 Lisímetro 5

2.2.2 Método combinado (Penman-Monteith) 6

2.2.2.1 Resistência do dossel (rc) 7

2.2.2.2 Resistência aerodinâmica (ra) 9

$\begin{array}{ll}2.3 \text { Termometria ao infravermelho } & 10\end{array}$

2.4 Uso da termometria ao infravermelho para caracterizar o estado 12

hídrico das culturas

3 MATERIAL E MÉTODOS $\quad 14$

3.1 Caracterização do local 14

3.2 Caracterização fisica do solo 14

3.3 Materiais 15

3.3.1 Aquisição dos dados meteorológicos $\quad 15$

3.3.2 Disposição das parcelas e do equipamento no campo 16

3.4 Métodos 18

3.4.1 Determinação do índice de área foliar (IAF) 18

3.4.2 Calibração dos termômetros ao infravermelho 18

3.4.3 Monitoramento da umidade do solo - tratamentos 18

3.4.4 Determinação da resistência do dossel 19 
3.4.4.1 Estimativa da resistência de dossel (rc) da cultura com o uso da termometria ao infravermelho

3 4.4.2 Determinação de rc como resíduo da equação de PenmanMonteith

3.4.5 Determinação e estimativa da evapotranspiração em períodos de 24 horas e períodos de luz

3.4.6 Determinação da resistência aerodinâmica (ra)

3.4.7 Estimativa da evapotranspiração de referência pela equação de Penman-Monteith

3.4.8 Análise dos resultados

3.4.9 Seleção dos dados 24

4 RESULTADOS E DISCUSSÃO 25

4.1 Calibração dos termômetros ao infravermelho 25

$\begin{array}{ll}4.2 \text { Análise de dados } & 27\end{array}$

4.3 Resistência do dossel

4.4 Evapotranspiração da cultura 36

4.5 Diferenças entre a temperatura do dossel da cultura e do $\operatorname{ar}$ (Tc-Ta) 41

5 CONCLUSÕES

REFERÊNCIAS BIBLIOGRÁFICAS $\quad 46$ 


\section{LISTA DE FIGURAS}

Página

1 Representação gráfica da teoria da "big leaf". $\quad 08$

2 Vista parcial da área com as três parcelas experimentais e disposição dos 16 termômetros ao infravermelho.

3 Detalhe do termômetro ao infravermelho utilizado para medir a temperatura do dossel da grama batatais.

4 Regressão linear entre a temperatura dos termômetros ao infravermelho da parcela 1(a), parcela 2 (b) e parcela 3 (c), e temperatura do calibrador.

5 Variação dos valores de temperatura e umidade relativa do ar, no período de 24 horas, para os dias estudados.

6 Variação dos valores de temperatura e umidade relativa do ar, no período de luz, para os dias estudados.

7 Variação dos valores de velocidade do vento no período de 24 horas e de 30 luz, para os dias estudados.

8 Radiação líquida para período de 24 horas e periodo de luz nos dias estudados.

9 Variação da resistência do dossel da grama com o uso da termometria ao infravermelho nas parcelas 1, 2 e 3, para periodos de 24 horas.

10 Variação da resistência de dossel da grama com o uso da termometria ao infravermelho nas parcelas 1,2 e 3 para períodos de luz. 
11 Evapotranspiração estimada pela equação de Penman-Monteith, utilizando valores de resistência do dossel da grama com o uso da termometria ao infravermelho, no período de 24 horas.

12 Evapotranspiração estimada pela equação de Penman-Monteith, utilizando 38 valores de resistência do dossel da grama com o uso da termometria ao infravermelho, em períodos de luz.

13 Evapotranspiração estimada pela equação de Penman-Monteith, com o uso 39 da termometria ao infravermelho em relação à evapotranspiração medida em lisimetro de pesagem para períodos de 24 horas.

14 Evapotranspiração estimada pela equação de Penman-Monteith, com o uso 40 da termometria ao infravermelho em relação à evapotranspiração medida em lisímetro de pesagem para períodos de luz.

15 Diferença de temperatura do dossel da grama e do ar para os dias estudados em períodos de 24 horas.

16 Diferença de temperatura do dossel da grama e do ar para os dias 42 estudados em períodos de luz.

17 Variação de (Tc-Ta), radiação líquida $(\mathrm{Rn})$ e temperatura do ar para os 42 dias $244(a, c), 248(b, d) 249$ (e, g) e 262 (f, h). 


\section{LISTA DE TABELAS}

Página

1 Análise física do solo.

2 Número de observações (n), coeficiente linear (a), coeficiente angular (b), índice de concordância (Id) e coeficiente de determinação $\left(\mathrm{r}^{2}\right)$, para os termômetros ao infravermelho das parcelas 1, 2 e 3 .

3 Valores médios de temperatura de ar, umidade relativa (UR), velocidade do vento (Vel. Vento) e temperatura do dossel da grama com o uso da termometria ao infravermelho (TIV) nas parcelas 1,2 e 3 para períodos de 24 horas.

4 Valores médios de temperatura de ar, umidade relativa (UR), velocidade 28 do vento (Vel. Vento) e temperatura do dossel da grama com o uso da termometria ao infravermelho (TIV) nas parcelas 1,2 e 3 para períodos de luz.

5 Valores de radiação líquida $(\mathrm{Rn})$, fluxo de calor no solo na parcela 1 (F.C. Parcela 1), parcela 2 (F.C. Parcela 2) e parcela 3 (F.C. Parcela 3), para períodos de 24 horas.

6 Valores de radiação líquida $(\mathrm{Rn})$, fluxo de calor no solo na parcela 1 (F.C. Parcela 1), parcela 2 (F.C. Parcela 2) e parcela 3 (F.C. Parcela 3), para períodos de luz.

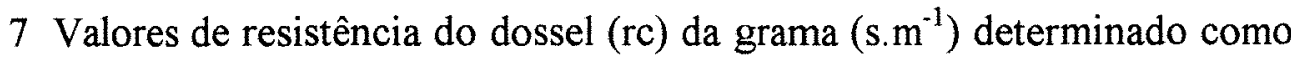
resíduo da equação de Penman-Monteith e estimados com o uso da termometria ao infravermelho para as parcelas 1,2 e 3 em períodos de 24 horas. 


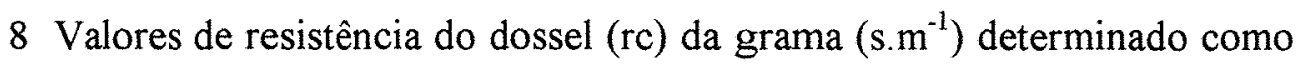
resíduo da equação de Penman-Monteith e estimados com o uso da termometria ao infravermelho para as parcelas 1, 2 e 3 em períodos de luz.

9 Valores de evapotranspiração $\left(\mathrm{mm} \cdot \mathrm{dia}^{-1}\right)$ determinados pelo lisímetro (ETo lisimetro) e estimados para as parcelas 1, 2 e 3 pela equação de Penman-Monteith (ETo PM) com o uso da termometria ao infravermelho, no periodo de 24 horas.

10 Valores de evapotranspiração (mm.dia ${ }^{-1}$ ) determinados pelo lisímetro (ETo lisímetro) e estimados para as parcelas 1,2 e 3 pela equação de Penman-Monteith (ETo PM) com o uso da termometria ao infravermelho, no periodo de luz. 


\title{
ESTIMATIVA DA RESISTÊNCIA DE DOSSEL (rC) DA GRAMA COM O USO DA TERMOMETRIA AO INFRAVERMELHO
}

\author{
Autor: Luís Fernando de Souza Magno Campeche \\ Orientador: Prof. Dr. Marcos Vinícius Folegatti
}

\section{RESUMO}

A evapotranspiração é uma das variáveis meteorológicas mais importantes para o melhor aproveitamento do recurso hídrico. No que diz respeito ao dimensionamento e manejo de sistemas de irrigação, o conhecimento da necessidade hídrica das culturas é de fundamental importância. Assim, os estudos de técnicas que visem uma melhor estimativa desta variável, são necessários.

Dos modelos matemáticos que descrevem a evapotranspiração das culturas, o proposto por Penman-Monteith é considerado um dos mais adequados, porém apresenta a limitação de usar variáveis de dificil mensuração em campo. O desenvolvimento de termômetros ao infravermelho portáteis, facilita a utilização do modelo, pois a técnica da termometria permite a estimativa dos valores de resistência de dossel, variável de maior dificuldade na determinação e de grande importância na utilização do referido modelo.

Os objetivos deste trabalho foram de estimar a resistência de dossel (rc) para a cultura da grama batatais (Paspalum notatum) pela técnica da termometria ao infravermelho e comparar com a resistência de dossel determinada como resíduo da equação de Penman-Monteith. 
Os valores de resistências de dossel, das variáveis meteorológicas, e da evapotranspiração foram avaliados para períodos de 24 horas e períodos de luz. A análise dos resultados permitiu verificar que o valor médio da resistência do dossel (rc) determinado como resíduo, em periodos de 24 horas foi de $70,2 \mathrm{s.m} \mathrm{m}^{-1}$. No periodo de luz determinou-se um valor maior de rc, correspondente a $164 \mathrm{~s} . \mathrm{m}^{-1}$. Os valores médios de rc estimados pela termometria ao infravermelho aumentaram com o aumento da tensão de água no solo, tanto no períodos de 24 horas como nos período de luz. 


\title{
THE CROP CANOPY RESISTANCE (rC) FOR GRASS ESTIMATION USING THE INFRARED THERMOMETER
}

\author{
Author: Luís Fernando de Souza Magno Campeche \\ Adviser: Prof. Dr. Marcos Vinícius Folegatti
}

\section{SUMMARY}

The estimation of the evapotranspiration (ET) is very important for managing water resources. The crop evapotranspiration is essential for designing and management of irrigation projects. Than, the studies of techniques that improve the estimation of ET are very necessary, despite of the enormous amount of papers already written about this subject.

The Penman-Monteith model that estimates the ET crop, is very appropriate, even so it presents the limitation that the variables are not always available in the field. The development of portable infrared thermometers can help to use the model, once it is possible to estimate the crop canopy resistance (rc), knowing the air and crop temperature, net radiation, wind speed and the relative humidity. The $\mathrm{rc}$ is a variable that is very difficult to measure directly from the plants.

The objective of this work were to estimate the rc for grass crop (Paspalum notatum) using the infrared thermometry technique in three different soil water tensions, and to estimate the rc values as a residue of the Penman-Monteith equation when the evapotranspiration was directly measured by a weighing lysimeter.

The values of the canopy resistance, of the climatic variables, and the evapotranspiration were studied for periods of 24 hours and light periods. The analysis 
of the results allowed to verify that the medium value of the canopy resistance (rc)

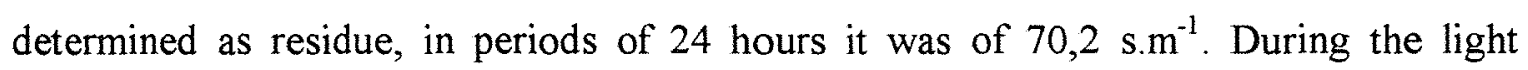
period, a larger value of $\mathrm{rc}$ was determined, corresponding to $164 \mathrm{s.m}^{-1}$. The medium values of rc estimated using the infrared thermometer increased as the soil water tension increased, for both periods. 


\section{INTRODUÇÃO}

O crescimento das populações e a sua conseqüente interferência no meio ambiente, nos levam a deduzir que precisamos conhecer os fatores limitantes da produção primária nas várias regiões do globo.

O volume limitado de água disponível para irrigação é um fator que está se restringindo a expansão da área irrigada. Desta forma, é necessário implementar práticas que permitam a racionalização da quantidade de água a ser utilizada na irrigação de modo a atender as necessidades hídricas das culturas, que estimados de modo errado conduzem ao sub ou super dimensionamento de projetos de irrigação.

Para tal, é preciso conhecer a evapotranspiração de cultura, podendo ser determinado direta ou indiretamente. As determinações diretas são as mais precisas, mas atualmente restringem-se à instituições de pesquisas, devido ao custo e complexidade da instalação e operação. As medidas indiretas caracterizam-se muitas vezes em estimativas bastante precisas, para tanto é necessário o desenvolvimento de pesquisas regionais para calibração de modelos.

É comum estimar o consumo hídrico de uma determinada cultura a partir da evapotranspiração de referência, corrigida por um coeficiente de cultivo (Kc), estimando assim a evapotranspiração da cultura. Nos próximos anos, este procedimento será substituído por técnicas mais precisas de estimativas de evapotranspiração, sendo esta estimada diretamente em uma só etapa pois, é de se esperar que o conceito e determinação de Kc sejam gradativamente substituído por resistência de dossel (rc), que, quando determinado tempo real, expressa valores mais confiáveis na equação de PenmanMonteith. 
O modelo de Penman-Monteith é considerado como o mais preciso na estimativa da evapotranspiração, pois leva em consideração as condições climáticas e a resistência que a planta oferece na transferência de vapor de água para atmosfera, que está relacionado à disponibilidade de água no solo. Entretanto, para que a adoção deste modelo seja viável, é necessário o desenvolvimento de trabalhos de pesquisas que estimem a resistência de dossel (rc), para várias culturas.

Este trabalho teve como objetivo estimar a resistência de dossel (rc) para a cultura da grama batatais (Paspalum notatum) pela técnica da termometria ao infravermelho e comparar com a resistência de dossel determinada como resíduo da equação de PenmanMonteith. 


\section{REVISÃO DE LITERATURA}

\subsection{Evapotranspiração}

O termo evapotranspiração compreende a perda de água de uma superfície úmida (solo e planta) e pela transpiração das plantas. A evapotranspiração é controlada pela disponibilidade de energia, pelo poder evaporante do ar e pela água disponível do solo às plantas. A disponibilidade de energia depende do local e da época do ano, a capacidade de secamento depende da temperatura e umidade relativa do ar e a disponibilidade de água do solo depende do tipo de solo, da cultura, estádio de desenvolvimento da cultura e do potencial da água no solo. O local é caracterizado pelas coordenadas geográficas (latitude e altitude) e pela topografia da região. A latitude determina o total diário de radiação solar a ser utilizado no processo evaporativo. Numa topografia acidentada, dependendo da estação do ano, terrenos com faces distintas terão disponibilidades diferentes de energia. A altitude influencia diretamente a temperatura do solo e do ar e a pressão atmosférica, que são fatores que afetam a evapotranspiração. Para um dado local, a disponibilidade de radiação é controlada pelo poder refletor da superficie, que é expresso pelo coeficiente de reflexão (albedo). Superficies mais claras refletem mais que as mais escuras, e, portanto, têm menos energia disponível. Uma vegetação mais escura, tipo floresta, reflete menos radiação solar que uma cultura ou gramado. (Pereira et al., 1997).

$\mathrm{Na}$ literatura, observa-se diversos conceitos para evapotranspiração. Thrornthwaite (1948) definiu evapotranspiração potencial como sendo a água utilizada por uma extensa superficie vegetada, em crescimento ativo e cobrindo totalmente o 
terreno, estando o solo bem suprido de água, ou seja, em nenhum instante a demanda atmosférica é restringida por falta de água.

Jensen (1973) define evapotranspiração de referência, como sendo a evapotranspiração máxima que ocorre numa cultura de alfafa (Mendicago sativa L), com altura de 30 a $50 \mathrm{~cm}$, numa dada condição climática, e com aproximadamente $100 \mathrm{~m}$ de área tampão. Doorenbos \& Pruitt (1975), definem evapotranspiração de referência aquela que ocorre em uma extensa superficie de grama com altura de 8 a $12 \mathrm{~cm}$, em crescimento ativo, cobrindo totalmente o solo e sem deficiência de água

Doorenbos \& Kassam (1979) definem evapotranspiração potencial como sendo a evapotranspiração de uma área extensa coberta de grama verde de 8 a $15 \mathrm{~cm}$ de altura, em ativo estádio de crescimento, livres de pragas ou doenças, sombreando totalmente o solo e sem escassez de água. Esses mesmos autores definem com evapotranspiração máxima em que as condições de água é suficiente para um crescimento e desenvolvimento sem restrição e representa a taxa de evapotranspiração máxima de uma cultura sadia que cresce em grandes áreas sob condições ótimas de manejo agronômico e de irrigação. Villa Nova \& Reichardt (1989) definem evapotranspiração máxima quando uma pequena área irrigada está rodeada por uma área seca e a área tampão não é suficiente para eliminar os efeitos advectivos do calor sensível, representando nestas condições um valor exagerado.

Pereira et al. (1997) definem evapotranspiração real como aquela que ocorre numa superficie vegetada, independente de sua área, de seu porte e das condições de umidade do solo. Portanto, evapotranspiração real é a que ocorre em quaisquer circunstância, sem imposição de qualquer condição de contorno. Logo, evapotranspiração real pode assumir tanto o valor potencial como o de oásis, ou outro qualquer.

Smith (1991) relata que, tradicionalmente a evapotranspiração de referência (ETo) é definida como sendo aquela que ocorre em uma cultura hipotética, com altura de 0,12 metros, albedo igual a $23 \%$, resistência da cobertura ao transporte de vapor d'água igual a $69 \mathrm{~s} . \mathrm{m}^{-1}$, que representaria a evapotranspiração de um gramado verde, de altura 
uniforme, em crescimento ativo, cobrindo totalmente a superficie do solo, e sem deficiência de água

\subsection{Métodos de medidas e estimativa de evapotranspiração}

Vários são os métodos de avaliação da evapotranspiração. A literatura é muito abrangente e relata diversas técnicas e equações para sua estimativa. Dentre as categorias diferentes, podemos definir os métodos diretos e os combinados. Os métodos diretos determinam a evapotranspiração, enquanto que os métodos combinados estimam seus valores. A seguir, são descritos dois métodos (direto e combinado) separadamente.

\subsubsection{Lisímetro}

Lisímetros são dispositivos cheios de solo, localizados no campo com a função de representar um ambiente específico para fornecer medidas diretas da evapotranspiração, cujo princípio é o balanço de massa ou mais usualmente o balanço volumétrico de água em um volume conhecido de solo. Existem três tipos de lisímetros: (1) de pesagem (balanço de massa); (2) não pesáveis, com lençol freático de nível constante; e (3) não pesáveis com drenagem livre (Aboukhaled et al., 1982)

Apesar de ser um método preciso, ainda assim os lisímetros apresentam limitações. Normalmente, as plantas tendem a crescer mais no interior do lisímetro (efeito buquê) ou crescer além dos limites da borda externa do lisímetro. Além das dificuldades em se manter as condições internas e externas dos lisímetros com as mesmas características da área representada, existem grandes dificuldades instrumentais. As diferenças em crescimento das culturas no interior dos lisímetros em relação à área externa, especialmente quando as plantas crescem mais no interior, provocam uma perturbação maior no movimento horizontal do ar aumentando o grau de turbulência do calor sensível do ar sobre a cultura e da transpiração da vegetação. A interceptação da radiação solar incidente pelas folhas também aumenta numa proporção que pode chegar a 40\% (Sediyama, 1996). 


\subsubsection{Método combinado (Penman-Monteith)}

Monteith (1965) obteve uma equação geral válida para qualquer tipo de vegetação, a partir da equação original de Penman, sob qualquer condição de estresse hídrico. Este método permite uma estimativa da evapotranspiração de referência a partir de dados de temperatura e umidade relativa do ar, radiação solar e velocidade do vento. $\mathrm{O}$ autor generalizou o modelo de Penman através de uma analogia com a lei de Ohm para circuitos elétricos, introduzindo no termo aerodinâmico da equação duas resistências à transferência do vapor d'água: a resistência do dossel da cultura (rc) e a resistência aerodinâmica (ra). O primeiro termo descreve as características fisiológicas da planta e o segundo descreve a influência da turbulência atmosférica (velocidade do vento, geometria da superfície) no processo de transporte de vapor d'água (Oke, 1992).

Segundo Bruin \& Holtslag (1982), este modelo constitui-se na mais completa expressão teórica para partição da radiação líquida disponível em uma superfície vegetada, em termos de calor sensível e calor latente.

O modelo de Penman-Monteith, embora tenha uma formulação teórica rigorosamente física, é de fácil entendimento e demanda para a sua utilização de informações meteorológicas, normalmente coletadas em estações padrões. Sua aplicação prática é limitada pelas dificuldades de se obter valores confiáveis e representativos para a resistência da cobertura vegetal, conforme relatado por Monteith (1985).

Atualmente, faz-se o uso de duas etapas para o cálculo da evapotranspiração das culturas: estima-se a evapotranspiração de referência e a seguir multiplica-se este valor por um coeficiente de cultura empírico (Doorenbos \& Pruitt, 1975). De acordo com Smith (1991), uma forma mais vantajosa de cálculo seria conduzir o processo de estimativa em uma só etapa, descartando a utilização dos coeficientes de cultura. Para que este objetivo seja alcançado, é necessário estimar diretamente a evapotranspiração da cultura pelo modelo de Penman-Monteith, através da aplicação de valores adequados de resistência aerodinâmica e resistência da cobertura vegetal.

Autores como Ben-Asher et al. (1989) afirmam que o modelo de PenmanMonteith será de pouco valor prático, a não ser que a resistência da cobertura vegetal 
venha a ser parametrizada a partir de propriedades da planta, do solo e da atmosfera, as quais conhecidas e de fácil mensuração. Esta dificuldade operacional faz com que este modelo seja utilizado como uma ferramenta para determinação da resistência da cobertura vegetal como resíduo, quando a evapotranspiração é conhecida, quando o desejável seria a situação inversa (Monteith, 1985).

\subsubsection{Resistência do dossel (rc)}

A solução que Monteith (1965) encontrou para desenvolver um método que considera os processos de transferência em um estômato e na atmosfera interna do dossel, é a que assumi que as trocas de calor sensível e latente (vapor d'água) entre o dossel e a atmosfera ocorrem em uma superficie plana e arbitrária, localizada no mesmo nível do fluxo de momento. Esse autor partiu do princípio de que a vegetação é representada por uma enorme folha (teoria da 'big leaf'), implicando que todas as folhas estão expostas às mesmas condições ambientais, e na superfície virtual onde ocorre todas as propriedades fisiológicas de todas as folhas do dossel (Lhome, 1991; Kroon e Bruin, 1993). Essa é a premissa necessária para se obter a resistência do dossel à difusão do vapor d'água, ou seja, admite-se um valor médio que seja representativo do dossel, e que, por sua vez, determina uma transpiração média.

Conforme a Figura 1, nessas condições, o dossel está a uma temperatura $T_{0}$, com

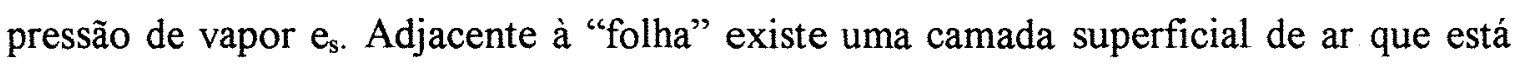
também com temperatura $T_{0}$, mas com pressão de vapor $e_{0}$, e isto induz uma transpiração LE1. Imediatamente acima desta camada, o ar está com temperatura $\mathrm{T}$ e pressão de vapor e, existindo uma resistência do ar ao transporte de vapor ( $\mathrm{ra}_{\mathrm{v}}$ ) que determina uma densidade de fluxo transpirativo LE2. Pela diferença de temperatura entre o dossel e o ar há transporte de calor sensível $(\mathrm{H})$ que também é governado pela resistência do ar ( $\left.\mathrm{rah}_{h}\right)$ (Monteith, 1965). 


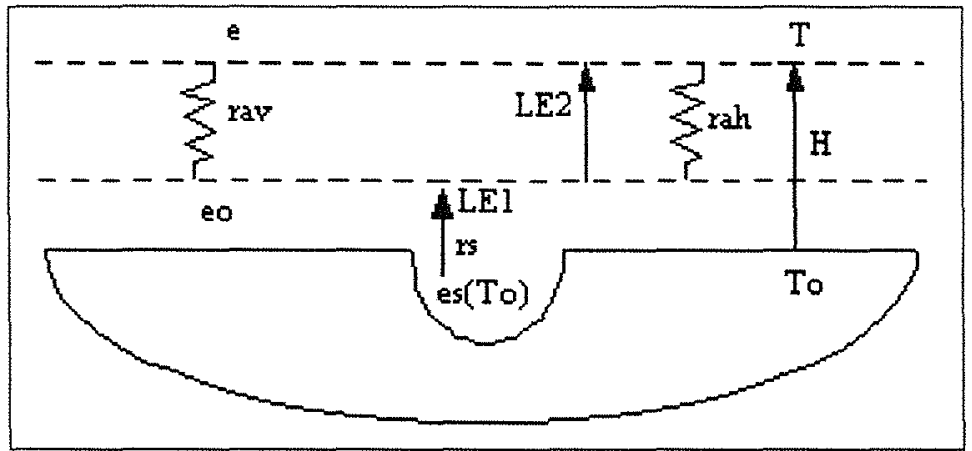

Figura 1. Representação gráfica da teoria da 'big leaf'. (Fonte: Pereira et al., 1997)

A resistência ao transporte de vapor do dossel da cultura (rc) é condicionada pela demanda atmosférica e pela disponibilidade de água no solo. Se a demanda não for plenamente atendida, rc aumenta com conseqüente redução na contribuição do termo advectivo ao total de evapotranspiração. Quando não há restrição ao atendimento da demanda, geralmente rc é pequena e menor que $\mathrm{ra}_{\mathrm{v}}$, e nessa situação a evapotranspiração se diferencia da evaporação apenas pelo efeito do albedo no balanço de energia e pela rugosidade da superficie que afeta a resistência aerodinâmica (Pereira et al., 1997).

As dificuldades para se estimar a resistência do dossel decorrem do fato dela ser uma função composta de muitos fatores ambientais e biológicos, tais como radiação solar, déficit de saturação de vapor d'água, disponibilidade de água no solo, índice de área foliar, entre outros, cujos efeitos individuais não são fáceis de serem isolados (Monteith, 1985)

Uma vez estabelecido o valor da resistência da cobertura vegetal, o modelo de Penman-Monteith tem se mostrado superior aos demais métodos combinados na estimativa da evapotranspiração das culturas, para uma ampla variedade de climas e localidades. Allen et al. (1989) apresenta uma equação para estimativa de rc, que é utilizada para comparar os resultados de diferentes localidades

Diversos autores evidenciaram a necessidade de se pesquisar a variação da resistência da cobertura vegetal (Magiotto, 1996; Folegatti, 1988; Hatfield, 1988; Russel, 1980; Grant, 1975). As pesquisas desenvolvidas com o objetivo de estudar a 
resistência da cobertura vegetal, apresentando sua relação com elementos de solo e clima, relatam valores bastante variados

Kobayashi (1996), trabalhando com termômetro ao infravermelho na cultura do feijão concluiu em seu trabalho que as maiores resistências estomáticas foram obtidas nos tratamentos mais estressados de água, em comparação com os tratamentos não estressados.

Resultados experimentais têm mostrado que ocorre melhoria nas estimativas da evapotranspiração pelo modelo de Penman-Monteith, quando se adota valores da resistência do dossel variáveis com a radiação líquida disponível. Esta variação leva em consideração os efeitos de intensidade da luz solar e o comprimento do dia (Allen, 1986).

Peres (1994) estimou a evapotranspiração da cultura da grama pelo modelo de Penman-Monteith e encontrou as melhores correlações com a evapotranspiração medida em lisímetro de drenagem quando usou valores de resistência de dossel da ordem de 80 s. $\mathrm{m}^{-1}$.

Monteith (1981) e Sharma (1983) sugerem que a mínima resistência ao

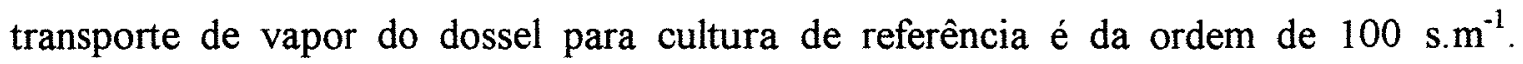
Segundo Monteith (1985), os valores da resistência de dossel assim obtidos são equivalentes aos estimados pelo método residual, através da aplicação do modelo de Penman-Monteith. Já Hatfield (1988) afirma que os valores conhecidos de rc para as diferentes culturas estão ao redor de $20 \mathrm{~s} . \mathrm{m}^{-1}$, para solos próximos à capacidade de campo, aumentando à medida que a umidade do solo diminui.

\subsubsection{Resistência aerodinâmica (ra)}

Segundo Monteith (1973), o conceito de resistência se aplica a qualquer sistema no qual os fluxos possam ser relacionados ao gradiente, e que quando o processo se trata só de difusão molecular, os coeficientes de difusão para momentum, calor e vapor d'água são similares na ordem de grandeza e em sua dependência com a temperatura. 
Porém, na atmosfera, onde a turbulência é o mecanismo dominante de transporte, os coeficientes de transporte são em ordem de grandeza maiores que o valor molecular correspondente e aumentam com a altura acima da superficie do solo. Allen (1986), por sua vez, definiu a resistência aerodinâmica à transferência do vapor d'água em condições de neutralidade no interior da camada limite.

Berkowicz \& Prahm (1982) afirmaram que as resistências aerodinâmicas são governadas pela turbulência atmosférica que é mantida principalmente pela transferência de calor e momentum. As resistências aerodinâmicas dependem, portanto, dessas grandezas. Por outro lado, é a interação do vento com a superfície a maior fonte de turbulência na camada superficial. De acordo com esses autores, a estimativa empírica da resistência aerodinâmica para o vapor d'água foi formulada por Penman (1948) e é uma função inversa da velocidade do vento à 2 metros de altura. Esta relação linear foi baseada em medidas diárias para superficies de água livre e, com pequenas modificações é utilizada ainda hoje nos estudos de evapotranspiração a longo prazo. Afirmam ainda que esta simplificação pode ser adequada quando se considera médias sobre períodos de um dia ou mais. Para valores horários, consideraram que o efeito da condição da estabilidade atmosférica no interior da camada limite é muito importante.

\subsection{Termometria ao infravermelho.}

A termometria ao infravermelho mede a radiação emitida pelo alvo e relaciona essa radiação com a temperatura de sua superficie, pela lei de Stefan-Boltzmann, o qual cita que a radiação emitida por um corpo qualquer é proporcional à quarta potência da temperatura absoluta de sua superficie, ou seja:

$$
\mathrm{R}=\varepsilon \sigma \mathrm{T}^{4}
$$

em que:

$\mathrm{R}=$ radiação emitida $\left(\mathrm{W} \mathrm{m}^{-2}\right)$

$\varepsilon=$ emissividade da superficie (adimensional) 


$$
\sigma=\text { constante de Stefan-Boltzmann }\left(5,674 \cdot 10^{-4} \mathrm{~W} \cdot \mathrm{m}^{-2} \cdot \mathrm{K}^{-4}\right)
$$

$\mathrm{T}=$ temperatura do corpo considerado $(\mathrm{K})$.

Muitos termômetros ao infravermelho têm filtros que admitem energia entre $8 \mathrm{e}$ $14 \mu \mathrm{m}$ de comprimento de onda para alcançar o sensor. Esse comprimento de onda compreende o máximo de emissão dos corpos negros às temperaturas normais e tem baixa absorção pelo vapor de água. A emissividade de superficies naturais entre esses comprimentos de onda é relativamente alta, porém, a absorção pelo vapor de água não pode ser sempre desprezada. Para medidas precisas de emissividade, essa absorção deve ser conhecida. Outra complicação é o fato de que parte da irradiação emitida pelas áreas vizinhas e refletida pela superfície nesse comprimento de onda também pode interferir no sensor, somando-se à radiação recebida no alvo (Jackson et al., 1981). A presença de nuvens altera o balanço de energia na superfície, o que não é considerado adequado, principalmente quando se trata de determinação de índices baseados na temperatura da cobertura (Folegatti, 1988).

Erros na determinação da temperatura do dossel da cultura podem ocorrer em virtude da calibração inadequada do instrumento, por causa da estimativa errada da emissividade ou por causa da má representatividade da porção utilizada na determinação (Jackson et al., 1981).

Berliner et al. (1984), estudando as características do balanço de energia da cultura relevantes para a termometria ao infravermelho, verificaram que mudanças instantâneas na velocidade do vento afetam a temperatura do dossel da cultura. Essa variação pode ser devida ao resfriamento ou à exposição de parte do dossel que estava anteriormente sombreada, porém os resultados indicaram que, em função da variação lenta da temperatura do dossel, pode-se assumir que a diminuição da temperatura associada à velocidade do vento, é devida, principalmente, ao resfriamento do dossel.

Um problema na interpretação das medidas do termômetro ao infravermelho é a falta de conhecimento do valor da emissividade da superficie de interesse. A temperatura fornecida pelo detector termal pode diferir substancialmente da verdadeira temperatura 
quando a emissividade é pouco menor do que 1 . A emissividade da superficie vegetada varia de 0,9 a 0,98 (Idso et al., 1969).

Das muitas causas de erros de medidas de temperatura da cobertura vegetal, Kalma \& Jupp (1990) obtiveram dados que indicam que os erros de reflexividade e de emissividade e o efeito do azimute são limitações importantes. Estes autores verificaram que o efeito do ângulo de visada pode ser considerado insignificante.

O'Toole \& Real (1986) avaliaram o efeito do ângulo zenital do sensor do termômetro e concluíram que havia diferenças de temperatura de até $13^{\circ} \mathrm{C}$ quando o ângulo zenital variou de $0 \mathrm{a} 80^{\circ}$.

\subsection{Uso da termometria ao infravermelho para caracterizar o estado hídrico das culturas}

As necessidades hídricas das culturas são normalmente expressas mediante a taxa de evapotranspiração, em mm.dia ${ }^{-1}$ ou período. Resultados experimentais de Denmead \& Shaw (1962), mostram que sob demanda atmosférica baixa, a planta consegue extrair água do solo até níveis bem baixos de água disponível e, se a demanda for alta, mesmo com bastante umidade no solo, a planta não consegue extraí-la numa taxa compatível com as suas necessidades, resultando em fechamento temporário dos estômatos para evitar ressecamento das folhas e conseqüente aquecimento desta.

A utilização da temperatura da cobertura vegetal para detectar estresse hídrico baseia-se no fato de que a água transpirada resfria a folha. À medida que a quantidade de água no solo diminui, a transpiração diminui e a temperatura da folha se eleva. Se pouca água é transpirada, as folhas ficarão mais quentes que o ar devido a absorção da radiação. Portanto, a disponibilidade hídrica altera a temperatura das plantas e, conseqüentemente, a radiação eletromagnética emitida. Com a medida dessa radiação emitida é possivel o estabelecimento de relações com a condição da planta quanto à disponibilidade hídrica (Epiphanio et al, 1989).

Walker \& Hatfield (1983) citam três condições básicas no uso da temperatura da cobertura vegetal (Tc) determinada pela termometria ao infravermelho na avaliação do 
déficit hídrico no solo em relação às plantas: a) a diferença de temperatura entre os vários tratamentos experimentais e o tratamento sem limitação hídrica, tomado como referencial; b) a variabilidade das temperaturas de repetidas medidas, que são usadas para indicar o nível de déficit hídrico; c) o uso da diferença de temperatura entre a superficie da cultura e a temperatura do ar, que tem sido demonstrado estarem ambas correlacionadas negativamente com o conteúdo relativo de água na folha e com o potencial de água na planta. Esses autores afirmam que o sucesso da determinação do déficit hídrico com a utilização da temperatura foliar ou do dossel da cultura depende de outros fatores, que também afetam a abertura dos estômatos, além do estado hídrico da planta, como é o caso da radiação, da temperatura, da umidade e dos gases contaminantes. Portanto, a elevação na temperatura das folhas pode não ser causada pela variação no conteúdo de água na planta, levando uma caracterização errada do déficit hídrico.

Khera \& Sandhu (1986) obtiveram a Tc da cana-de-açúcar, em parcelas bem irrigadas, de $2^{\circ}$ a $7^{\circ} \mathrm{C}$ menores que em parcelas estressadas e Tc tanto das parcelas bem irrigadas como estressadas de $1{ }^{\circ} \mathrm{C}$ a $12^{\circ} \mathrm{C}$ menor que a temperatura do ar (Ta). $\mathrm{O}$ fato da Tc das parcelas estressadas ser menor do que $\mathrm{Ta}$, associado aos dados de evapotranspiração, indica que a perda de calor latente dessas parcelas foi igual ou superior ao fluxo do saldo de radiação para longos períodos, em virtude da contribuição da energia advectiva do ambiente externo seco e quente.

Costa (1995), trabalhando com termometria ao infravermelho para caracterizar o momento de irrigação, concluiu que, apesar de não haver uma diferença acentuada de temperatura entre o tratamento de sequeiro e de irrigação, a diferença entre as temperaturas do dossel e do ar caracterizaram muito bem as distintas situações do estado hídrico da cultura. 


\section{MATERIAL E MÉTODOS}

\subsection{Caracterização do local}

O presente trabalho foi desenvolvido na área experimental de irrigação da Fazenda Areão do Departamento de Engenharia Rural, da Escola Superior de Agricultura "Luiz de Queiroz"-ESALQ/USP, situada no município de Piracicaba-SP (Lat. $22^{\circ} 42^{\prime} \mathrm{S}$; Long. $47^{\circ} 39^{\prime} \mathrm{W}$; altitude de $520 \mathrm{~m}$ ).

Segundo a classificação climática de Koppen, Piracicaba possui clima Cwa sub tropical úmido, com estiagem no inverno, temperatura média anual de $21,1{ }^{\circ} \mathrm{C}$ e precipitação média anual de $1.247 \mathrm{~mm}$.

\subsection{Caracterização física do solo}

O solo da área é classificado como Terra Roxa Estruturada (Alfisol), série Luíz de Queiroz tendo uma declividade média de 2,3\%.

Segundo SILVA (1996), o solo apresenta as seguintes características e propriedades fisicas nas profundidades de 0-0,15 e 0,15-0,30 m, Tabela 1 . 
Tabela 1. Análise fisica do solo.

\begin{tabular}{c|ccc|cc}
\hline $\begin{array}{c}\text { Camada } \\
\text { (m) }\end{array}$ & \multicolumn{3}{c|}{$\begin{array}{c}\text { Granulometria } \\
(\%)\end{array}$} & \multicolumn{2}{c}{$\begin{array}{c}\text { Densidade } \\
\left(\mathbf{g} \cdot \mathrm{cm}^{-3}\right)\end{array}$} \\
\hline & Areia & Silte & Argila & Partículas & Solo \\
\hline $0-0,15$ & 24,11 & 24,70 & 51,18 & 2,49 & 1,31 \\
$0,15-0,30$ & 15,56 & 16,76 & 67,67 & 2,58 & 1,47 \\
\hline
\end{tabular}

\subsection{Materiais}

\subsubsection{Aquisição dos dados meteorológicos}

As informações meteorológicas foram obtidas de uma estação automática instalada na área experimental. Para registro contínuo de dados, foi usado um sistema de armazenamento de dados (modelo CR10), que armazena informações geradas a cada segundo, em média de 30 minutos, com os sensores abaixo relacionados:

- Temperatura e umidade relativa do ar a $2 \mathrm{~m}$ de altura (modelo HMP35C temperature/RH Probe-Campbell), com acurácia de $0,1{ }^{\circ} \mathrm{C}$ de temperatura e $3 \%$ de umidade relativa.

- Radiação solar global a $3 \mathrm{~m}$ de altura (modelo LI200X Pyranometer- Li-cor Inc).

- Velocidade do vento a 2 metros de altura (modelo 014A Wind Speed SensorMet One Instruments; threshold $=0,45 \mathrm{~m} . \mathrm{s}^{-1}$ ).

- Direção do vento a $2 \mathrm{~m}$ de altura (modelo 024A Wind Direction Sensor- Met One Instruments; threshold $=0,45 \mathrm{~m} \cdot \mathrm{s}^{-1}$ e acurácia de $5 \%$ ).

- Precipitação a 1,5 m de altura (modelo TE525 Tipping Bucket Rain GageWeather Bureal, precisão de 0,1 mm).

- Radiação líquida a $1 \mathrm{~m}$ de altura da cobertura vegetal (modelo Q7. Net Radiometer- REBS; espectro de 0,25 a $60 \mu \mathrm{m}$ ).

- Placa de fluxo de calor a 0,03 m de profundidade (modelo HFT-3 Soil Heat Flux Plate- Campbell). 


\subsubsection{Disposição das parcelas e do equipamento no campo.}

A área em que foi instalado o experimento possui $3.150 \mathrm{~m}^{2}$ vegetados com grama batatais (Paspalum notatum).

O experimento foi constituído de três parcelas, sendo a parcela 1 instalada na área evaporante do lisímetro de pesagem, e as outras duas montadas diretamente no solo as quais foram revestidas com lonas plásticas de $150 \mu \mathrm{m}$ até 1 metro de profundidade, afim de evitar fluxo lateral de água. As parcelas montadas no solo possuem dimensões de $1,5 \mathrm{~m}$ de comprimento e $1 \mathrm{~m}$ de largura, totalizando uma área de $1,5 \mathrm{~m}^{2}$ cada parcela denominadas parcelas 2 e 3 (Figura 2).

O lisímetro possui área evaporante de $0,92 \mathrm{~m}^{2}$ e peso total de aproximadamente $920 \mathrm{~kg}$, apoiadas sobre três células de cargas que se encontram conectadas a um sistema de armazenamento de dados. Detalhes de construção e operação desse conjunto evapotranspirométrico são encontrados em Silva (1996).

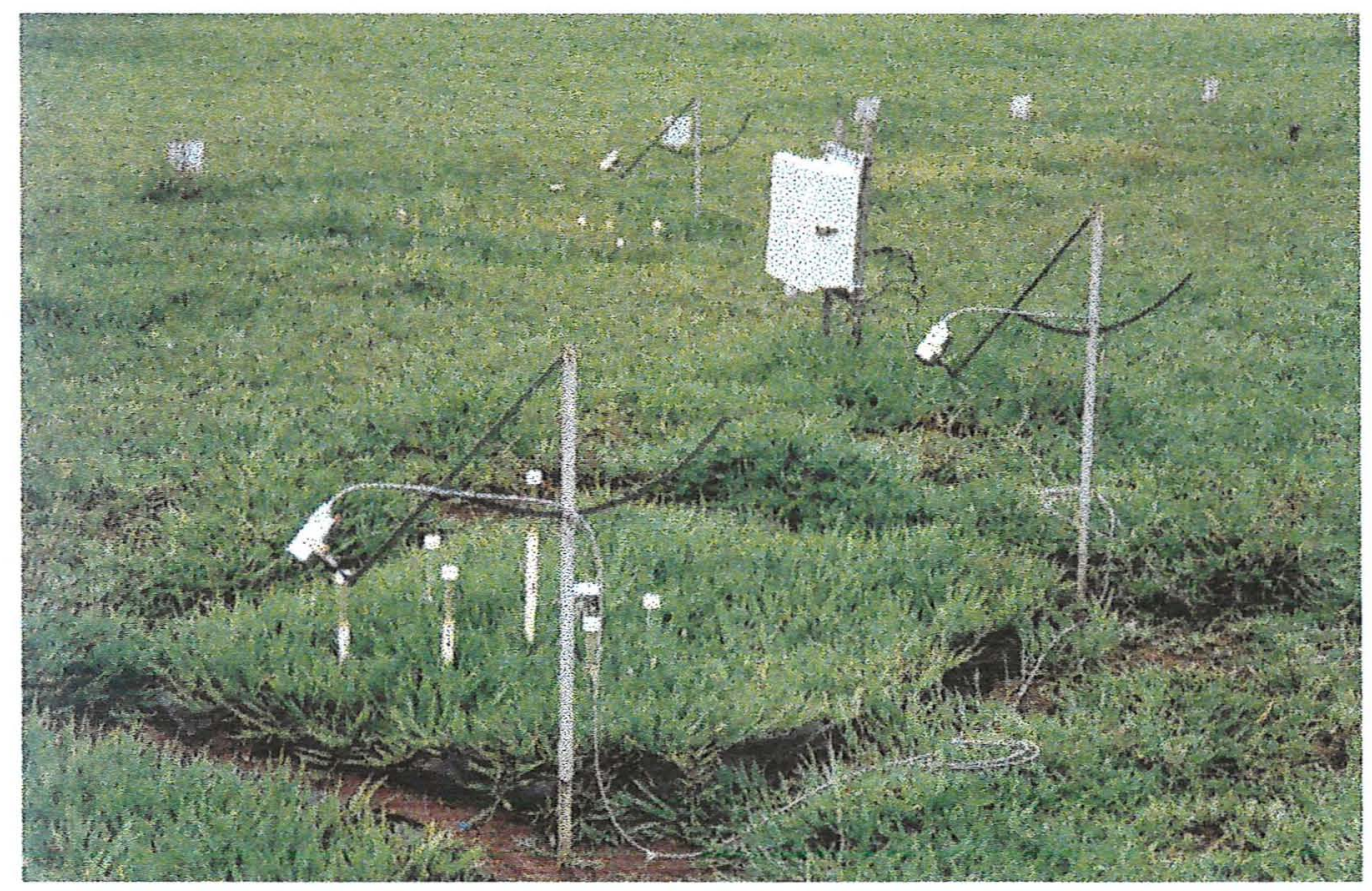

Figura 2. Vista parcial da área com as três parcelas experimentais e disposição dos termômetros ao infravermelho. 
A temperatura do dossel da cultura foi medida por meio de três termômetros ao infravermelho, instalados em cada parcela experimental com as seguintes características: modelo 4000-4GL Infrared Temperature Transducer - Everest Interscience Inc.; resolução de $0,1^{\circ} \mathrm{C}$ e acurácia de $0,5^{\circ} \mathrm{C}$. O aparelho foi instalado visando a cobertura vegetal nas parcelas com um ângulo de $45^{\circ} \mathrm{com}$ a horizontal, no sentido sul. As leituras eram realizadas a cada minuto e armazenadas como a médias a cada $30 \mathrm{~min}$. O termômetro possui um ângulo de visada de $15^{\circ}$, numa faixa de leitura do espectrômetro de 8 a $14 \mu \mathrm{m}$ e emissividade ajustada de 0,975 para cultura de referência (Figura 3).

Foram realizadas, ao longo da condução do experimento, calibrações para os termômetros, visando ajustar uma equação de calibração que corrigisse possíveis distorções nas medidas efetuadas pelo equipamento.

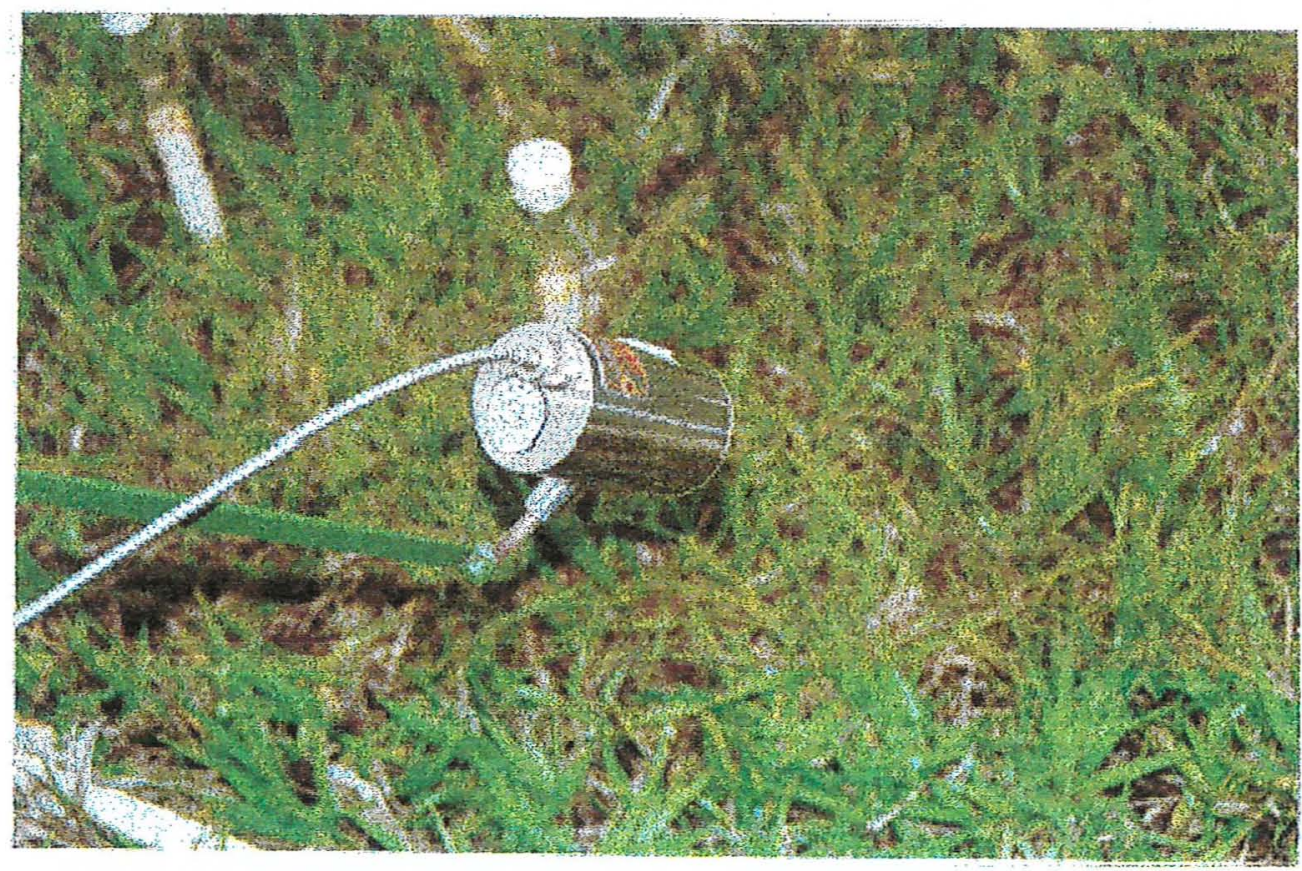

Figura 3. Detalhe do termômetro ao infravermelho utilizado para medir a temperatura do dossel da grama batatais. 


\subsection{Métodos}

\subsubsection{Determinação do índice de área foliar da grama (IAF)}

Para determinação do índice de área foliar foi demarcada uma área de $2,5 \mathrm{~m}^{2}$ distante aproximadamente 4 metros das parcelas. Em seguida a área foi subdividida em cinco partes iguais de $0,5 \mathrm{~m}^{2}$ onde a grama de cada sub-área foi cortada e acondicionada separadamente em sacos de papel. Somente uma parte do total de cinco foi imediatamente levada para um medidor de área foliar (Li-cor modelo 3100), sendo esta posteriormente secada em estufa a $55^{\circ} \mathrm{C}$ durante 48 horas, obtendo-se uma relação entre o peso seco e a área foliar (padrão). Após esse procedimento, as outras quatro sub-áreas foram secadas em estufa na mesma temperatura e tempo, sendo as áreas foliares estimadas em função do padrão determinado anteriormente. O IAF foi determinado pela relação entre as áreas foliares e a área total de cada parcela, sendo considerado o valor médio do IAF das cinco repetições.

\subsubsection{Calibração dos termômetros ao infravermelho}

Para assegurar de que a temperatura lida pelos termômetros fosse a temperatura real do dossel da grama, foram realizadas calibrações dos termômetros durante o período de coleta de dados, para isso, foi usado um calibrador de termômetros ao infravermelho (calibration source, modelo 1000-Everest interscience Inc.), com faixa de leitura de 0 a $60^{\circ} \mathrm{C}$.

Os termômetros foram dispostos de forma a medir as variações de temperatura do calibrador, pelo aquecimento e resfriamento, permitindo assim, a elaboração de uma curva de calibração entre a temperatura do termômetro com a obtida no calibrador.

\subsubsection{Monitoramento da umidade do solo - tratamentos}

A fim de monitorar a umidade do solo, foram instalados na área evaporante do lisímetro (Parcela 1) 2 tensiômetros, na profundidade de $0,15 \mathrm{~m}$ e 2 tensiômetros na 
profundidade de $0,30 \mathrm{~m}$. Nas parcelas 2 e 3, foram instalados 6 tensiômetro em cada parcela, sendo 2 a $0,15 \mathrm{~m}, 2$ a $0,30 \mathrm{~m}$ e os outros dois a 0,40 e $0,60 \mathrm{~m}$, respectivamente.

O controle de umidade do solo nas parcelas foi realizado da seguinte maneira: na parcela 1 (lisímetro de pesagem) foi feito o acompanhamento do peso do lisímetro, mantido sempre entre 920 e $930 \mathrm{~kg}$, não permitindo uma variação de peso superior a 10 $\mathrm{kg}$. Assim, fez-se aplicação periódica de água para reposição da umidade, sendo que a máxima lâmina aplicada por irrigação correspondeu a $11 \mathrm{~mm}$. Realizou-se também o monitoramento da umidade na profundidade de $0,15 \mathrm{~m}$, com leituras de tensiômetros a cada três dias. Isso permitiu considerar que a umidade do solo na parcela 1 correspondeu sempre à capacidade de campo, durante todo o período do experimento. Nas parcelas $2 \mathrm{e}$ 3, o monitoramento foi diário, realizado com auxílio de tensiômetros instalados a $0,15 \mathrm{~m}$ de profundidade em que a tensão máxima admitida foi de $60 \mathrm{kPa}$ na parcela 2 e na parcela 3 as tensões foram maiores que $60 \mathrm{kPa}$.

\subsubsection{Determinação da resistência do dossel}

\subsubsection{Estimativa da resistência do dossel (rc) da cultura com o uso da termometria ao infravermelho.}

Segundo Jackson et al. (1981), com o uso da técnica da termometria ao infravermelho para determinação da temperatura da cobertura vegetal, pode-se obter uma equação que calcula a relação entre rc e ra. Como o valor de ra pode ser estimado, podemos isolar o valor de rc em períodos de 24 horas e periodos de luz (período em que a radiação líquida é positiva).

$$
\frac{r c_{t c}}{r a}=\frac{\rho \cdot N \cdot 3600 \cdot c p \cdot(e c-e a)}{\gamma \cdot r a\left[(R n-G)-\frac{\rho \cdot c p \cdot N \cdot 3600 \cdot(T c-T a)}{r a}\right]}-1
$$


em que:

$\mathrm{rG}_{\mathrm{c}}=$ resistência da cobertura usando temperatura do dossel da cultura $\left(\mathrm{s} \cdot \mathrm{m}^{-1}\right)$

$\mathrm{ra}=$ resistência aerodinâmica à transferência de calor sensível e vapor d'água $\left({\left.\mathrm{s} . \mathrm{m}^{-1}\right)}^{-1}\right.$

$\rho=$ densidade do $\operatorname{ar}\left(\mathrm{kg} \cdot \mathrm{m}^{-3}\right)$

$\mathrm{cp}=$ calor específico do $\operatorname{ar}\left(\mathrm{MJ} \cdot \mathrm{kg}^{-1} \cdot{ }^{\circ} \mathrm{C}^{-1}\right)$

$\mathrm{N}=$ número de horas do periodo considerado (h)

$\mathrm{ec}=$ pressão de saturação de vapor à temperatura da cobertura vegetal $(\mathrm{kPa})$

ea $=$ pressão atual de vapor à temperatura do ar $(\mathrm{kPa})$

$\gamma=$ constante psicrométrica $\left(\mathrm{kPa} \cdot{ }^{\circ} \mathrm{C}^{-1}\right)$

$\mathrm{Rn}=$ radiação líquida $\left(\mathrm{MJ} \cdot \mathrm{m}^{-2} \cdot \mathrm{dia}^{-1}\right)$

$\mathrm{G}=$ densidade de fluxo de calor do solo $\left(\mathrm{MJ} \cdot \mathrm{m}^{-2} \cdot \mathrm{dia}^{-1}\right)$

$\mathrm{Tc}=$ temperatura do dossel da cultura $\left({ }^{\circ} \mathrm{C}\right)$

$\mathrm{Ta}=$ temperatura do $\operatorname{ar}\left({ }^{\circ} \mathrm{C}\right)$

\subsubsection{Determinação de rc como resíduo da equação de Penman-Monteith}

Para comparação dos valores de resistência de dossel estimados pela termometria ao infravermelho, foi usada a equação de Penman-Monteith, que permitiu o cálculo de rc como residuo a partir da evapotranspiração da cultura de referência medida no lisímetro de pesagem e das variáveis meteorológicas medidas no local do experimento.

$$
\mathrm{rc}_{\mathrm{res}}=\frac{s \cdot r a \cdot(R n-G)+\rho \cdot c p \cdot N \cdot 3600 \cdot(e s-e a)}{\gamma \cdot \lambda E}-r a \cdot\left(\frac{s}{\gamma}+1\right)
$$

em que:

$\mathrm{rc}_{\mathrm{res}}=$ resistência ao transporte de vapor do dossel da cultura como resíduo $\left(\mathrm{s} . \mathrm{m}^{-1}\right)$

$\mathbf{s}=$ tangente à curva de pressão de saturação de vapor no ponto da temperatura do ar $\left(\mathrm{kPa}^{\circ} \mathrm{C}^{-1}\right)$

$\lambda E=$ densidade de fluxo de calor latente $\left(\mathrm{MJ} \cdot \mathrm{m}^{-2} \cdot \mathrm{dia}^{-1}\right)$ 


\subsubsection{Determinação e estimativa da evapotranspiração em períodos de 24 horas e períodos de luz}

Para a determinação da evapotranspiração em períodos de 24 horas, fez-se o somatório em planilha eletrônica das diferenças negativas (saída de água do sistema) dos valores obtidos no lisímetro de pesagem a cada meia hora. Para o período de luz (periodo em que a radiação líquida torna-se positiva), fez-se o somatório das diferenças negativas somente para o período na qual a radiação líquida foi positiva.

$\mathrm{Na}$ estimativa da evapotranspiração pela equação de Penman-Monteith para períodos de 24 horas foram usados valores médios diários da radiação líquida e fluxo de calor no solo, temperatura e umidade relativa do ar e resistência aerodinâmica para os cálculos das variáveis necessárias para o modelo. Na estimativa da evapotranspiração para períodos de luz, usou-se os valores médios da radiação líquida e fluxo de calor no solo, temperatura e umidade relativa do ar, resistência aerodinâmica e resistência de dossel no período em que a radiação líquida foi positiva.

\subsubsection{Determinação da resistência aerodinâmica (ra)}

A equação usada na estimativa da resistência aerodinâmica foi baseada nos resultados obtidos por Allen et al. (1989) para condições de estabilidade neutra e parametrizada por Smith (1991):

$$
\mathrm{ra}=\frac{208}{\mathrm{U}_{2}}
$$

em que:

$\mathrm{ra}=$ resistência aerodinâmica à transferência de calor sensível e vapor de água $\left(\mathrm{s} \cdot \mathrm{m}^{-1}\right)$

$\mathrm{U}_{2}=$ velocidade do vento medida a 2 metros de altura $\left(\mathrm{m} . \mathrm{s}^{-1}\right)$ 
3.4.7 Estimativa da evapotranspiração de referência pela equação de PenmanMonteith

Para estimativa da evapotranspiração de referência, foi usada a equação de Penman-Monteith a partir de valores conhecidos de rc estimados pelos métodos acima descritos. A equação de Penman-Monteith pode ser escrita como:

$$
\lambda \mathrm{ET}=\frac{s(R n-G)+\rho \cdot c p \cdot N \cdot 3600 \cdot \frac{(e s-e a)}{r a}}{s+\gamma\left(1+\frac{r c}{r a}\right)}
$$

em que:

$\lambda E T=$ densidade de fluxo de vapor $\left(\mathrm{MJ} \mathrm{m}^{-2} \mathrm{dia}^{-1}\right)$

$\lambda=$ calor latente de evaporação $\left(\mathrm{MJ} \mathrm{kg}^{-1}\right)$

O valor da densidade do ar foi dado por:

$$
\rho=\frac{332,091}{T a r+275}
$$

em que:

Tar = temperatura média do ar no periodo $\left({ }^{\circ} \mathrm{C}\right)$

A pressão de saturação do vapor de água à temperatura do ar foi calculada por:

$$
\text { es }=0,6108 \mathrm{EXP}\left(\frac{17,27 . T a r}{\operatorname{Tar}+237,3}\right)
$$

em que:

es = pressão de saturação do vapor de água à temperatura do ar $(\mathrm{kPa})$ 
A pressão atual de vapor de água será calculada por:

$$
\text { ea }=\text { es. } \frac{U R}{100}
$$

em que:

ea $=$ pressão atual do vapor de água $(\mathrm{kPa})$

UR = umidade relativa do ar média do período considerado (\%)

O valor da tangente à curva de pressão de saturação de vapor será calculado pela equação:

$$
\mathrm{s}=\frac{4098 . e s}{(T a+237,3)^{2}}
$$

em que:

$\mathrm{S}=$ tangente à curva de pressão de saturação do vapor no ponto dado pela temperatura do $\operatorname{ar}\left(\mathrm{kPa} .{ }^{\circ} \mathrm{C}^{-1}\right)$

O valor da constante psicrométrica $(\gamma)$ é dado pela seguinte equação:

$$
\gamma=0,0016286 . \frac{P}{\lambda}
$$

em que:

$\mathrm{P}=$ pressão atmosférica local $(\mathrm{kPa})$

$\lambda=$ calor latente de evaporação $\left(2,45 \mathrm{MJ} \cdot \mathrm{kg}^{-1}\right)$

\subsubsection{Análise dos resultados}

Para comparação dos resultados, foram feitas análises de regressão linear simples de evapotranspiração estimada pela equação de Penman-Monteith e medida pelo lisímetro de pesagem, nos períodos de 24 horas e período de luz, onde o lisímetro de pesagem foi considerado como padrão.

A utilização isolada do coeficiente de determinação $\left(r^{2}\right)$ muitas vezes pode não estar relacionado com o tamanho da diferença entre um valor padrão e um valor previsto por modelos de estimativas, o que pode levar a erros de interpretações. Foi utilizado o 
índice (Id) de concordância (Willmott, 1981), que expressa a dispersão dos pontos em relação à reta $1: 1$, em conjunto com o coeficiente de determinação. Este índice pode variar de 0 (total discordância) a 1 (total concordância).

$$
\mathrm{Id}=1-\frac{\sum(P i-O i)^{2}}{\sum(|P i-O|+|O i-O|)^{2}}
$$

em que:

$\mathrm{Pi}=$ valor estimado

$\mathrm{Oi}=$ valor observado

$\mathrm{O}=$ média dos valores observados

\subsubsection{Seleção dos dados}

O período de coleta de dados iniciou no dia 31/08 (Dia Juliano 243), quando as parcelas receberam os níveis de estresse estabelecidos, até o dia 19/09 (D.J. 262), totalizando 20 dias de coleta. A análise dos dados constituiu em verificar dias em que todos os sensores estiveram operando adequadamente, quando não foram realizadas calibrações de sensores, dias em que a precipitação foi menor que $1 \mathrm{~mm}$ e dias quando a tensão de água no solo foi igual a $60 \mathrm{kPa}$ na Parcela 2. Com base nestes critérios, foram selecionados 11 dias para a realização da análise do presente trabalho. 


\section{RESULTADOS E DISCUSSÃO}

\subsection{Calibração dos termômetros ao infravermelho}

Os resultados das análises de regressões entre as temperaturas lidas no calibrador e as leituras dos termômetros ao infravermelho, encontram-se na Tabela 2.

A análise da Tabela 2 permite verificar que o modelo linear descreveu adequadamente a relação entre as temperaturas, tendo em vista os elevados valores obtidos para o Índice de Concordância de Willmott e o coeficiente de determinação. Vale salientar que o coeficiente angular encontra-se próximo da unidade, retratando assim, pequena dispersão entre os valores de temperatura do calibrador e os estimados pelos termômetros ao infravermelho.

Tabela 2. Número de observações (n), coeficiente linear (a), coeficiente angular (b), índice de concordância (Id) e coeficiente de determinação $\left(r^{2}\right)$, para os termômetros ao infravermelho das parcelas 1,2 e 3 .

\begin{tabular}{|c|c|c|c|c|c|}
\hline & \multicolumn{4}{|c|}{$\mathrm{T}_{\text {ajustada }\left({ }^{\circ} \mathrm{C}\right)}=\mathrm{a}+\mathrm{b} \cdot \mathrm{T}_{\text {termômetro }\left({ }^{\circ} \mathrm{C}\right)}$} & \multirow[b]{2}{*}{$r^{2}$} \\
\hline & n & a & $\mathrm{b}$ & Id & \\
\hline Parcela1 & 399 & 0,3585 & 0,9641 & 0,999 & 0,999 \\
\hline Parcela 2 & 390 & 1,3885 & 0,9068 & 0,995 & 0,998 \\
\hline Parcela 3 & 418 & $-0,2474$ & 0,9754 & 0,998 & 0,998 \\
\hline
\end{tabular}

$\mathrm{Na}$ Figura 4, estão apresentados os valores das temperaturas obtidas com os termômetros ao infravermelho e pelo calibrador. Verifica-se pela reta $1: 1$, que apesar do 


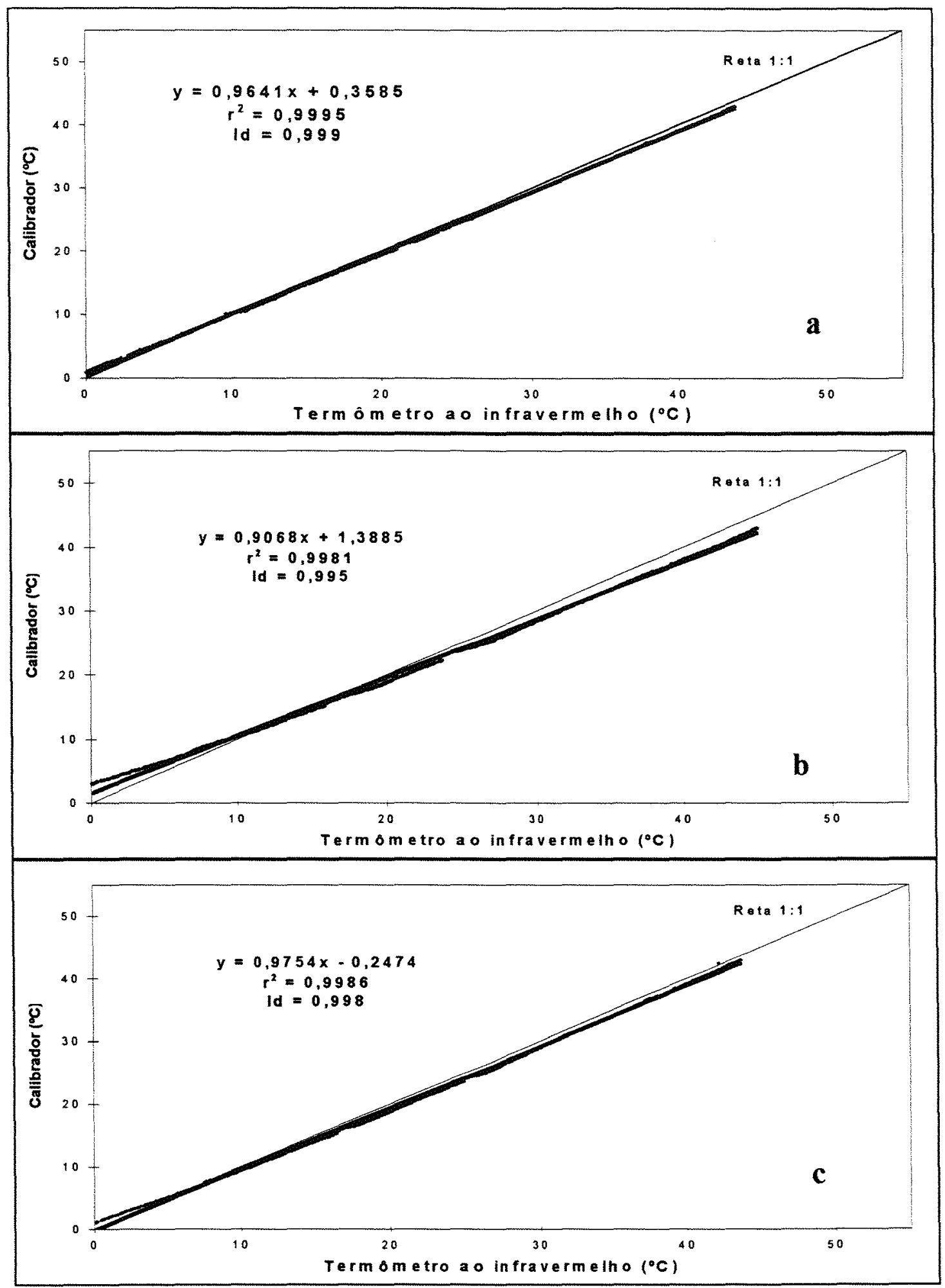

Figura 4. Regressão linear entre a temperatura dos termômetros ao infravermelho da parcela 1 (a), parcela 2 (b) e parcela 3 (c) e temperatura do calibrador. 
pequeno desvio, são necessárias calibrações para utilizar os termômetros ao infravermelho na estimativa da temperatura do dossel da culturas. As variações de temperaturas registradas durante a calibração foram de 41,$8 ; 43,0$ e $41,7^{\circ} \mathrm{C}$, para os termômetros 1,2 e 3 , respectivamente.

\subsection{Análise de dados}

$\mathrm{Na}$ Tabela 3, encontram-se os valores médios de temperatura e umidade relativa do ar, velocidade do vento e temperatura do dossel da grama para o período de 24 horas. $\mathrm{O}$ maior valor de temperatura do ar observada no periodo foi $24,3^{\circ} \mathrm{C}$ no dia 247 e o menor $19,8^{\circ} \mathrm{C}$ no dia 261 , com média correspondente a $22,5^{\circ} \mathrm{C}$. A umidade relativa do ar, variou de $74,2 \%$ a $48,6 \%$, com média de $60,6 \%$. Na Figura 5 encontra-se plotados os valores de temperatura e umidade relativa do ar, no período de 24 horas para os dias estudados. A velocidade máxima do vento para o período foi $2,4 \mathrm{~m} \cdot \mathrm{s}^{-1}$, e média de 1,9 $\mathrm{m} . \mathrm{s}^{-1}$. A média das temperaturas de dossel usando termômetros ao infravermelho foi de 21,$6 ; 23,2$ e $23,5^{\circ} \mathrm{C}$ para as parcelas 1,2 e 3 respectivamente.

Tabela 3. Valores médios de temperatura do ar, umidade relativa (UR) velocidade do vento (Vel. Vento) e temperatura do dossel da grama com o uso do termômetro ao infravermelho (TIV) nas Parcela 1,2 e 3 para períodos de 24 horas.

\begin{tabular}{|c|c|c|c|c|c|c|}
\hline $\begin{array}{l}\text { Dia } \\
\text { Juliano } \\
\end{array}$ & $\begin{array}{c}\text { Temp. ar } \\
\text { ('C) }\end{array}$ & $\begin{array}{l}\text { U.R. } \\
(\%)\end{array}$ & $\begin{array}{c}\text { Vel. Vento. } \\
\left(\mathrm{m} . \mathrm{s}^{-1}\right)\end{array}$ & $\begin{array}{c}\mathrm{TIV} 1 \\
\left({ }^{\circ} \mathrm{C}\right)\end{array}$ & $\begin{array}{l}\operatorname{TIV} 2 \\
\left({ }^{\circ} \mathrm{C}\right)\end{array}$ & $\begin{array}{l}\text { TIV3 } \\
\left({ }^{\circ} \mathrm{C}\right) \\
\end{array}$ \\
\hline 243 & 22,6 & 56,6 & 1,79 & 21,5 & 23,3 & 23,1 \\
\hline 244 & 22,1 & 54,5 & 1,85 & 20,2 & 21,8 & 22,2 \\
\hline 245 & 21,9 & 50,9 & 1,74 & 20,4 & 21,6 & 22,19 \\
\hline 246 & 23,0 & 48,6 & 1,84 & 20,8 & 22,1 & 22,9 \\
\hline 247 & 24,3 & 56,1 & 1,42 & 22,7 & 24,7 & 24,8 \\
\hline 248 & 22,2 & 68,3 & 2,11 & 21,6 & 22,1 & 22,5 \\
\hline 249 & 21,3 & 74,2 & 2,38 & 22,2 & 23,3 & 23,3 \\
\hline 250 & 20,7 & 68,6 & 1,43 & 20,3 & 22,1 & 22,0 \\
\hline 252 & 27,0 & 51,7 & 2,35 & 23,0 & 25,2 & 26,2 \\
\hline 261 & 19,8 & 70,6 & 2,38 & 21,3 & 22,9 & 23,1 \\
\hline 262 & 22,3 & 66,2 & 1,81 & 23,4 & 25,1 & 25,5 \\
\hline
\end{tabular}


$\mathrm{Na}$ Tabela 4, encontram-se os valores de temperatura e umidade relativa do ar, velocidade do vento e temperatura do dossel da grama para o periodo de luz. A temperatura do ar neste período variou de $31,9^{\circ} \mathrm{C}$ a $24,8^{\circ} \mathrm{C}$, com média de $26,3^{\circ} \mathrm{C}$, e a umidade relativa de $60,9 \%$ a $35,7 \%$, com média de $47,4 \%$. A Figura 6 , representa os valores médios de temperatura e umidade relativa do ar para o período de luz nos dias estudados. Para o periodo de luz a velocidade máxima do vento foi $3,1 \mathrm{~m} . \mathrm{s}^{-1}$, com média de 2,3 m.s. ${ }^{-1}$. Na Figura 7, estão representados os valores de velocidade média do vento para o período de 24 horas e período de luz nos dias estudados.

Os maiores valores de temperatura de dossel foram observados na parcela onde a tensão de água foi maior (parcela 3). Os valores médios de temperatura do dossel apresentaram ordem crescente de grandeza à proporção que aumentava a tensão de água no solo de 28,$5 ; 31,3$ e $33,2^{\circ} \mathrm{C}$ para as parcela 1,2 e 3 , respectivamente.

Tabela 4. Valores médios de temperatura do ar, umidade relativa (UR) velocidade do vento (Vel. Vento) e temperatura do dossel da grama com o uso do termômetro ao infravermelho (TIV) nas Parcela 1, 2 e 3 para períodos de luz.

\begin{tabular}{|c|c|c|c|c|c|c|}
\hline $\begin{array}{c}\text { Dia } \\
\text { Juliano }\end{array}$ & $\begin{array}{c}\text { Temp. ar } \\
\left({ }^{\circ} \mathrm{C}\right)\end{array}$ & $\begin{array}{l}\text { U.R. } \\
(\%)\end{array}$ & $\begin{array}{c}\text { Vel. Vento. } \\
\left(\mathrm{m}^{-1} \mathbf{s}^{-1}\right.\end{array}$ & $\begin{array}{l}\text { TIV } 1 \\
\left({ }^{\circ} \mathrm{C}\right)\end{array}$ & $\begin{array}{c}\text { TIV } 2 \\
\left({ }^{\circ}\right)^{2} \\
\end{array}$ & $\begin{array}{l}\text { TIV3 } \\
\left({ }^{\circ} \mathrm{C}\right)\end{array}$ \\
\hline 243 & 26,77 & 42,66 & 2,05 & 29,30 & 32,26 & 33,23 \\
\hline 244 & 26,37 & 42,57 & 2,18 & 28,62 & 31,26 & 33,74 \\
\hline 245 & 26,72 & 35,68 & 1,97 & 28,84 & 30,82 & 33,53 \\
\hline 246 & 26,67 & 37,93 & 2,40 & 27,18 & 29,42 & 32,02 \\
\hline 247 & 28,30 & 40,95 & 1,65 & 29,26 & 32,85 & 34,23 \\
\hline 248 & 25,10 & 58,38 & 2,83 & 26,60 & 27,52 & 29,25 \\
\hline 249 & 24,77 & 60,86 & 2,19 & 28,37 & 30,73 & 31,87 \\
\hline 250 & 24,46 & 54,98 & 1,81 & 28,57 & 31,99 & 33,33 \\
\hline 252 & 31,58 & 37,10 & 3,08 & 28,75 & 32,56 & 35,34 \\
\hline 261 & 23,20 & 56,89 & 2,75 & 27,86 & 31,15 & 32,77 \\
\hline 262 & 25,54 & 53,43 & 1,91 & 29,98 & 33,55 & 35,56 \\
\hline
\end{tabular}

A área em que foi realizado o presente trabalho possui dimensões de $35 \mathrm{X} 90$ metros vegetados com grama batatais. Tendo em vista o tamanho da área, a advecção foi considerada na interpretação e análise dos dados. 


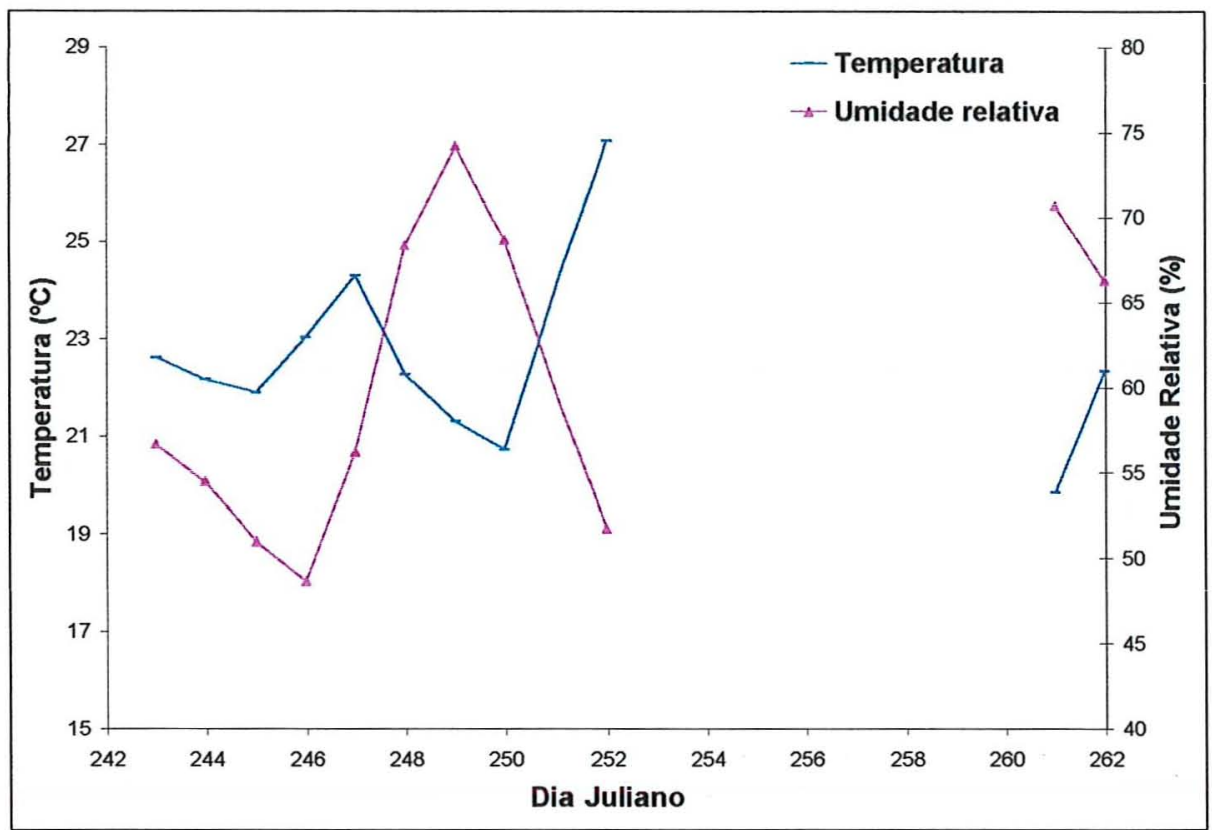

Figura 5. Variação dos valores de temperatura e umidade relativa do ar, no período de 24 horas, para os dias estudados.

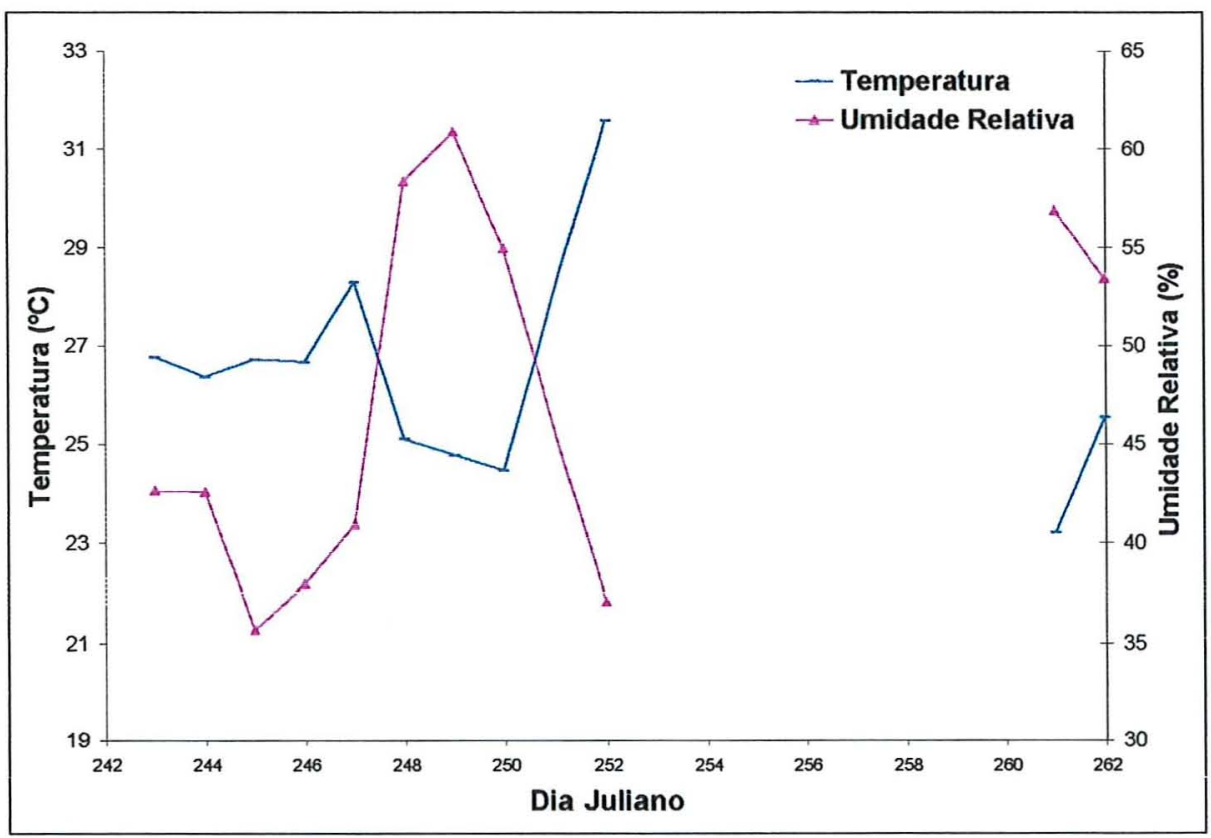

Figura 6. Variação dos valores de temperatura e umidade relativa do ar, no período de luz, para os dias estudados. 


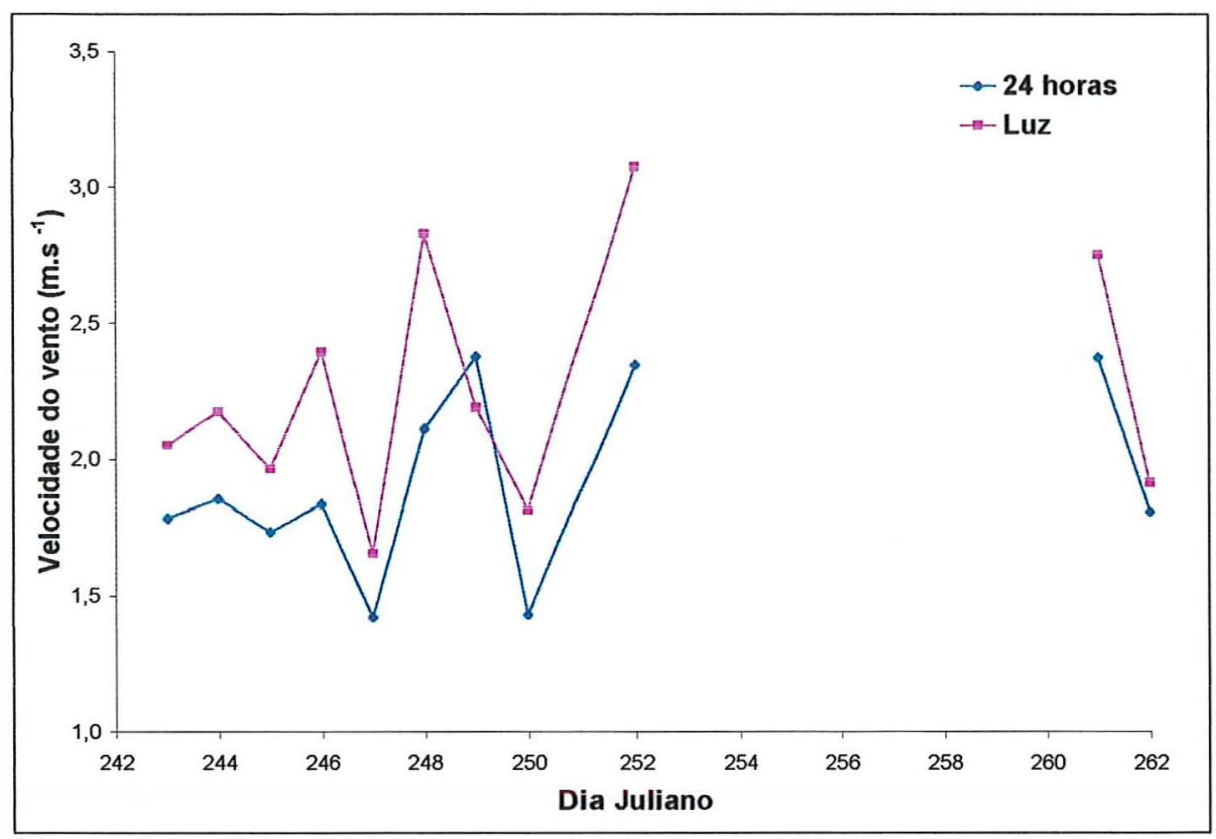

Figura 7. Variação dos valores de velocidade do vento no período de 24 horas e de luz, para os dias estudados

Na Tabela 5 estão representados os valores médios de radiação líquida e fluxo de calor no solo das parcelas 1, 2 e 3 no período de 24 horas. A radiação líquida é a variável meteorológica mais importante do balanço de energia. $\mathrm{O}$ valor máximo para o período de 24 horas foi $12.787 \mathrm{~kJ} \cdot \mathrm{m}^{-2} \cdot \mathrm{dia}^{-1}$ ocorrida no dia 261 e mínimo de $5.258 \mathrm{~kJ} \cdot \mathrm{m}^{-2} \cdot \mathrm{dia}^{-1}$ ocorrida no dia 248 com média durante o período de $10.236 \mathrm{~kJ} \cdot \mathrm{m}^{-2} \cdot \mathrm{dia}^{-1}$.

$\mathrm{Na}$ Tabela 6 estão representados os valores médios de radiação líquida e fluxo de calor no solo para períodos de luz. O valor máximo da radiação líquida foi de 14.235 $\mathrm{kJ} \cdot \mathrm{m}^{-2} \cdot \mathrm{dia}^{-1}$, e o mínimo de $6.387 \mathrm{~kJ} \cdot \mathrm{m}^{-2} \cdot \mathrm{dia}^{-1}$, com média de $11.653 \mathrm{~kJ} \cdot \mathrm{m}^{-2} \cdot \mathrm{dia}^{-1}$. Notou-se também uma acentuada queda nos valores de radiação líquida no dia 248 , devido a presença de nuvens. Esta baixa radiação líquida refletiu em menores valores de evapotranspiração para todas as parcelas observadas. A média dos valores de fluxo de calor no solo em períodos de luz apresentaram ordem decrescente de grandeza à medida que aumentava a tensão de água no solo, de 855,$9 ; 825,7$ e 625,7 kJ.m ${ }^{-2} \cdot$ dia $^{-1}$, respectivamente. 
$\mathrm{Da}$ análise das variáveis meteorológicas, verificou-se que as maiores amplitudes ocorreram no período de luz, tornando necessário uma avaliação mais criteriosa desta fase, no consumo total de água pelas culturas.

Tabela 5. Valores de radiação líquida (Rn), fluxo de calor no solo na Parcela 1 (F.C. Parcela 1), Parcela 2 (F.C. Parcela 2) e Parcela 3 (F.C. Parcela 3), para períodos de 24 horas.

\begin{tabular}{|c|c|c|c|c|}
\hline Dia Juliano & $\begin{array}{l}\mathrm{Rn} \\
\left(\mathrm{kJ} \mathrm{m}^{-2} \cdot \mathrm{dia}^{-1}\right)\end{array}$ & $\begin{array}{l}\text { F.C. Par. } 1 \\
\left(\mathrm{~kJ} \mathrm{~m}^{-2} \cdot \mathrm{dia}^{-1}\right)\end{array}$ & $\begin{array}{c}\text { F.C. Par. } 2 \\
\left(\mathbf{k J ~ m}^{-2} \mathrm{dia}^{-1}\right)\end{array}$ & $\begin{array}{l}\text { F.C. Par. } 3 \\
\left(\mathbf{k J ~ m}^{-2} \mathrm{dia}^{-1}\right)\end{array}$ \\
\hline 243 & $10.573,7$ & 340,4 & 125,6 & 166,6 \\
\hline 244 & $9.767,4$ & 210,3 & $-147,8$ & 21,3 \\
\hline 245 & $9.979,1$ & 130,8 & $-259,3$ & $-39,9$ \\
\hline 246 & $9.118,8$ & 116,5 & $-194,4$ & $-44,1$ \\
\hline 247 & $9.372,2$ & 417,0 & 352,6 & 340,2 \\
\hline 248 & $5.258,0$ & $-85,5$ & $-439,8$ & $-192,9$ \\
\hline 249 & $10.887,9$ & 309,5 & 16,1 & 0,0 \\
\hline 250 & $12.284,3$ & 61,8 & $-233,0$ & $-136,5$ \\
\hline 252 & $10.016,3$ & 270,2 & 180,7 & 228,6 \\
\hline 261 & $12.787,3$ & 145,5 & $-418,3$ & $-249,8$ \\
\hline 262 & $12.559,7$ & 636,9 & 354,5 & 398,4 \\
\hline
\end{tabular}

Tabela 6. Valores de radiação líquida (Rn), fluxo de calor no solo na Parcela 1 (F.C. Parcela 1), Parcela 2 (F.C. Parcela 2) e Parcela 3 (F.C. Parcela 3), para períodos de luz.

\begin{tabular}{|c|c|c|c|c|}
\hline Dia Juliano & $\begin{array}{c}\mathbf{R n}^{-2} \\
\left(\mathrm{~kJ} \mathrm{~m}^{-2} \cdot \mathrm{dia}^{-1}\right)\end{array}$ & $\begin{array}{l}\text { F.C. Parcela } 1 \\
\left.\text { (kJ m}^{2} \text { dia }^{-1}\right)\end{array}$ & $\begin{array}{c}\text { F.C. Parcela } 2 \\
\left(\mathrm{KJ} \mathrm{m}^{-2} \text { dia }^{-1}\right)\end{array}$ & $\begin{array}{l}\text { F.C. Parcela } 3 \\
\left(\mathrm{~kJ} \mathrm{~m}^{-2} \text { dia }^{-1}\right)\end{array}$ \\
\hline 243 & $12.016,70$ & 888,96 & 899,97 & 710,07 \\
\hline 244 & $11.153,96$ & 880,91 & 788,44 & 635,37 \\
\hline 245 & $11.846,71$ & 876,32 & 812,60 & 651,26 \\
\hline 246 & $10.442,35$ & 715,76 & 714,51 & 500,38 \\
\hline 247 & $10.471,43$ & 854,10 & $1.006,10$ & 707,47 \\
\hline 248 & $6.387,80$ & 426,81 & 303,06 & 260,25 \\
\hline 249 & $12.653,31$ & 986,59 & 959,06 & 630,33 \\
\hline 250 & $13.948,99$ & 952,57 & 914,78 & 631,97 \\
\hline 252 & $11.372,86$ & 741,23 & 787,32 & 614,23 \\
\hline 261 & $14.235,77$ & 946,74 & 758,21 & 607,64 \\
\hline 262 & $13.657,66$ & $1.145,29$ & $1.138,54$ & 934,49 \\
\hline
\end{tabular}


Na Figura 8 estão representados graficamente os valores de radiação líquida no período de 24 horas e períodos de luz para os dias estudados.

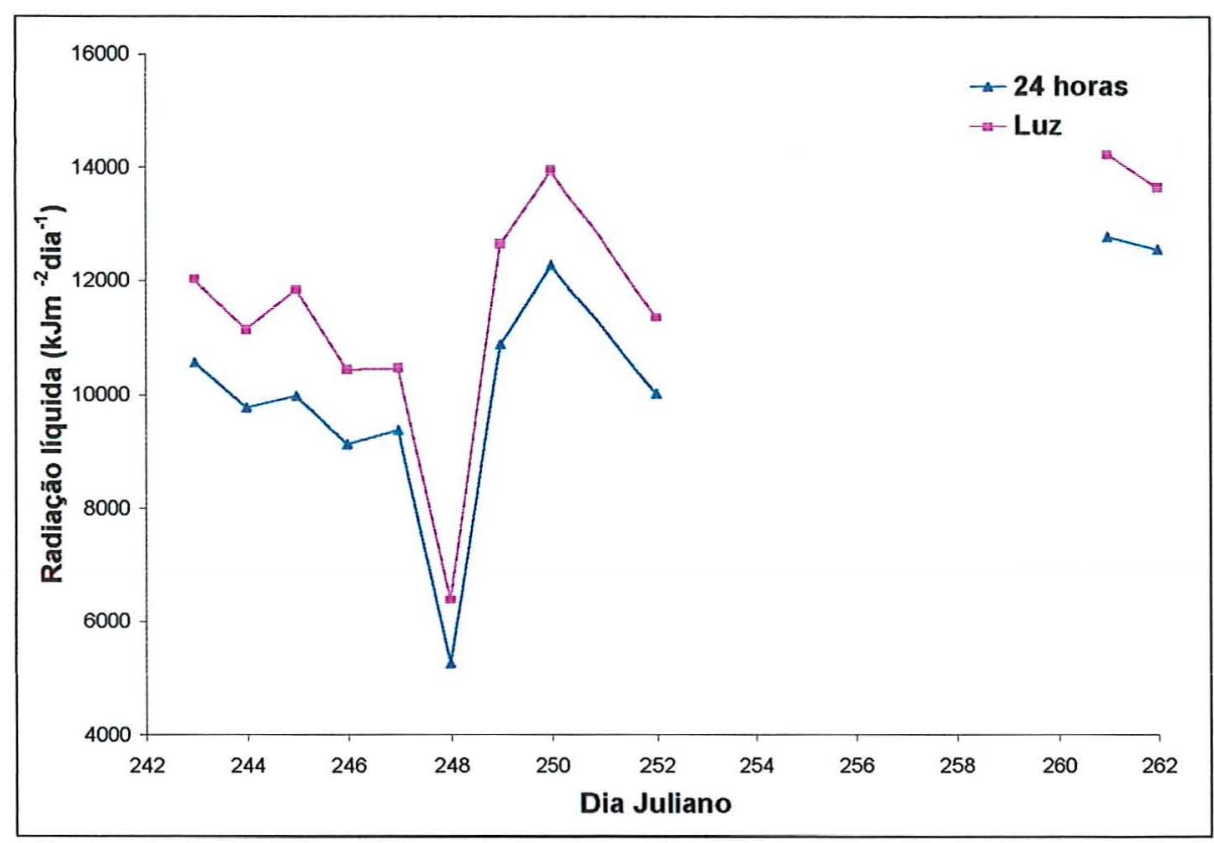

Figura 8. Radiação líquida para período de 24 horas e período de luz nos dias estudados.

\subsection{Resistência do dossel}

$\mathrm{Na}$ Tabela 7 encontram-se os valores de resistência de dossel à difusão de vapor d'água determinado como resíduo da equação de Penman-Monteith a partir de valores de ETo medidos no lisímetro de pesagem, e os valores de resistência do dossel estimados pela técnica da termometria ao infravermelho nas parcelas 1,2 e 3 para períodos de 24 horas. O valor médio da resistência de dossel, determinados como resíduo no períodos de 24 horas, foi 70,2 s.m , $^{-1}$, valor muito próximo ao parametrizado por Smith (1991), de 69 s. $\mathrm{m}^{-1}$. Magiotto (1996), por sua vez, trabalhando nas mesmas condições experimentais, porém em época diferente, encontrou um valor médio de 144 s.m. ${ }^{-1}$. Entre os valores médios de resistência de dossel encontrados na literatura, Hatfield (1988) sugere a adoção de $20 \mathrm{~s} . \mathrm{m}^{-1}$ para condição de evapotranspiração potencial. No entanto Monteith (1985) sugere valores de resistência de 50 s. $\mathrm{m}^{-1}$, pois valores de resistência menores do 
que esta ordem de grandeza superestimam a evapotranspiração. Peres (1994) encontrou valores de resistência da ordem de $80 \mathrm{~s} . \mathrm{m}^{-1}$ para evapotranspiração da grama para o estado de São Paulo.

O menor valor médio de resistência de dossel encontrado como resíduo da utilização da equação de Penman-Monteith em relação aos valores observados por Magiotto (1996) podem ser explicados pelo menor desenvolvimento vegetativo da grama no periodo de estudo, sendo constatado pelo menor índice de área foliar (IAF). O IAF medido no período foi igual a 1,0, valor esse bem abaixo do recomendado por Allen et al. (1989) de 2,88 como ideal para a cultura de referência. Grant (1975), trabalhando com cevada, observou que a resistência do dossel diminuía à medida que a cultura cobria totalmente o solo. Jonhs et al. (1983), trabalhando com grama verificaram também uma redução na resistência de dossel à medida que aumentava a área foliar da cultura.

Tabela 7. Valores de resistência do dossel (rc) da grama (s. $\left.\mathrm{m}^{-1}\right)$ determinado como resíduo da equação de Penman-Monteith e estimados com o uso da termometria ao infravermelho para as parcelas 1,2 e 3 , em períodos de 24 horas.

\begin{tabular}{ccccc}
\hline Dia Juliano & $\begin{array}{c}\text { rc } \\
\text { (Resíduo) }\end{array}$ & $\begin{array}{c}\text { rc } \\
\text { (Parcela 1) }\end{array}$ & $\begin{array}{c}\text { rc } \\
\text { (Parcela 2) }\end{array}$ & $\begin{array}{c}\text { rc } \\
\text { (Parcela 3) }\end{array}$ \\
\hline 243 & 69,26 & 25,21 & 92,27 & 83,25 \\
244 & 87,79 & 13,54 & 66,13 & 83,18 \\
245 & 46,28 & 30,96 & 67,18 & 92,24 \\
246 & 145,51 & 42,01 & 88,07 & 124,88 \\
247 & 77,78 & 15,75 & 101,75 & 110,55 \\
248 & 81,05 & 99,74 & 122,83 & 168,91 \\
249 & 32,62 & 43,84 & 93,71 & 90,78 \\
250 & 32,62 & $-55,84$ & $-10,74$ & $-12,65$ \\
252 & 116,48 & 16,39 & 86,09 & 131,28 \\
261 & 75,76 & 42,53 & 100,38 & 112,34 \\
262 & 7,09 & 38,44 & 108,49 & 128,39 \\
\hline Média & $\mathbf{7 0 , 2}$ & $\mathbf{2 8 , 4}$ & $\mathbf{8 3 , 3}$ & $\mathbf{1 0 1 , 2}$ \\
\hline
\end{tabular}


Os valores médios de resistência de dossel estimados pela termometria ao infravermelho para períodos de 24 horas (Tabela 7), foram de 28,4;83,3 e 101,2 s.m s. $^{-1}$ para as parcelas 1, 2 e 3, respectivamente. Foi observado valores de resistência negativa para as três parcelas no dia 250,0 que possivelmente está relacionado com valores elevados da radiação líquida (Tabela 5) associado à baixa velocidade do vento (Tabela 3), apesar da literatura não apresentar explicação para tal ocorrência, pois, teoricamente, o valor mínimo de resistência seria igual a zero, caso em que a equação de PenmanMonteith descreve a condição de evaporação livre de água ou de superficies molhadas (Monteith, 1985; Thom, 1975; Brutsaert, 1982).

$\mathrm{Na}$ Figura 9, estão apresentados os valores de resistência de dossel para as parcelas 1,2 e 3 no período de 24 horas. Verificou-se uma mesma tendência nas curvas que descrevem as variações de resistência do dossel (rc) nos dias analisados, tendo em vista a variação semelhante dos valores de rc nas parcelas. Constatou-se que os valores de resistência de dossel foram diretamente proporcionais aos níveis de estresse aplicados, visto que nas parcelas mais estressadas foram observados as maiores resistências, tendo em vista que as tensões de água no solo nas parcelas foram pré estabelecidas.

Os valores de resistência de dossel para períodos de luz, são apresentados na Tabela 8 e Figura 10. Os valores de resistência de dossel para periodos de luz foram superiores aos encontrados no período de 24 horas. Nas parcelas 1,2 e 3 os valores médios de resistência com o uso da termometria ao infravermelho foram de 64,3; 139,5 e $207,35 \mathrm{s.m}^{-1}$, respectivamente. A resistência de dossel média calculada como resíduo foi

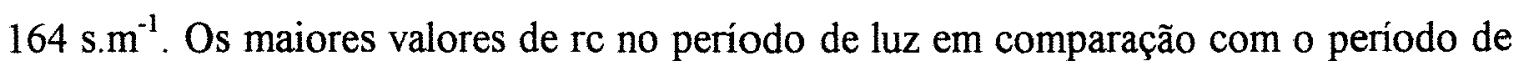
24 horas eram esperados, uma vez que as variáveis meteorológicas envolvidas no balanço de energia apresentam uma maior amplitude no período de luz que em 24 horas.

A análise da Figura 10, permite verificar que, de maneira semelhante ao ocorrido no periodo de 24 horas, existe uma relação direta entre os valores de rc e a tensão de água no solo, caracterizada pelo aumento dos valores de rc, à medida que se diferenciava a tensão de água nas parcelas. 


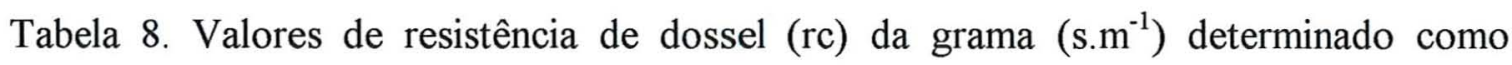
resíduo da equação de Penman-Monteith e estimados com o uso da termometria ao infravermelho para as parcelas 1,2 e 3 , em períodos de luz.

\begin{tabular}{ccccc}
\hline Dia Juliano & $\begin{array}{c}\text { rc } \\
\text { (Resíduo) }\end{array}$ & $\begin{array}{c}\text { rc } \\
\text { (Parcela 1) }\end{array}$ & $\begin{array}{c}\text { rc } \\
\text { (Parcela 2) }\end{array}$ & $\begin{array}{c}\text { rc } \\
\text { (Parcela 3) }\end{array}$ \\
\hline 243 & 185,78 & 69,58 & 150,39 & 177,62 \\
244 & 149,76 & 72,29 & 142,19 & 229,34 \\
245 & 135,87 & 73,70 & 121,69 & 204,11 \\
246 & 184,32 & 73,91 & 134,47 & 226,08 \\
247 & 151,94 & 52,66 & 160,21 & 200,27 \\
248 & 145,37 & 129,00 & 170,92 & 292,80 \\
249 & 140,67 & 43,51 & 104,88 & 133,59 \\
250 & 186,98 & 22,86 & 99,41 & 131,15 \\
252 & 236,90 & 55,54 & 152,77 & 263,30 \\
261 & 218,09 & 68,05 & 160,11 & 222,33 \\
262 & 70,25 & 46,47 & 137,08 & 199,73 \\
\hline Média & $\mathbf{1 6 4}$ & $\mathbf{6 4 , 3 2}$ & $\mathbf{1 3 9 , 5}$ & $\mathbf{2 0 7 , 3}$ \\
\hline
\end{tabular}

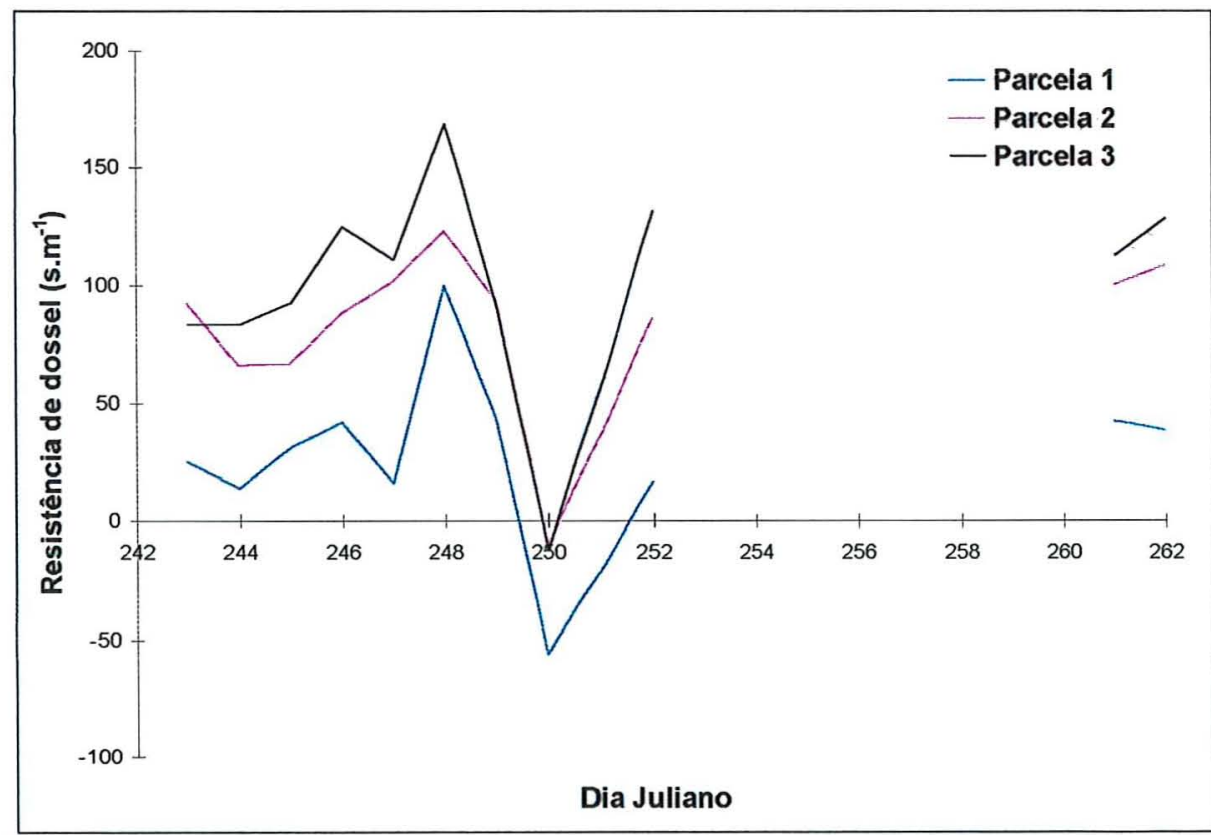

Figura 9 Variação da resistência do dossel da grama com o uso da termometria ao infravermelho nas parcelas 1,2 e 3 para períodos de 24 horas. 


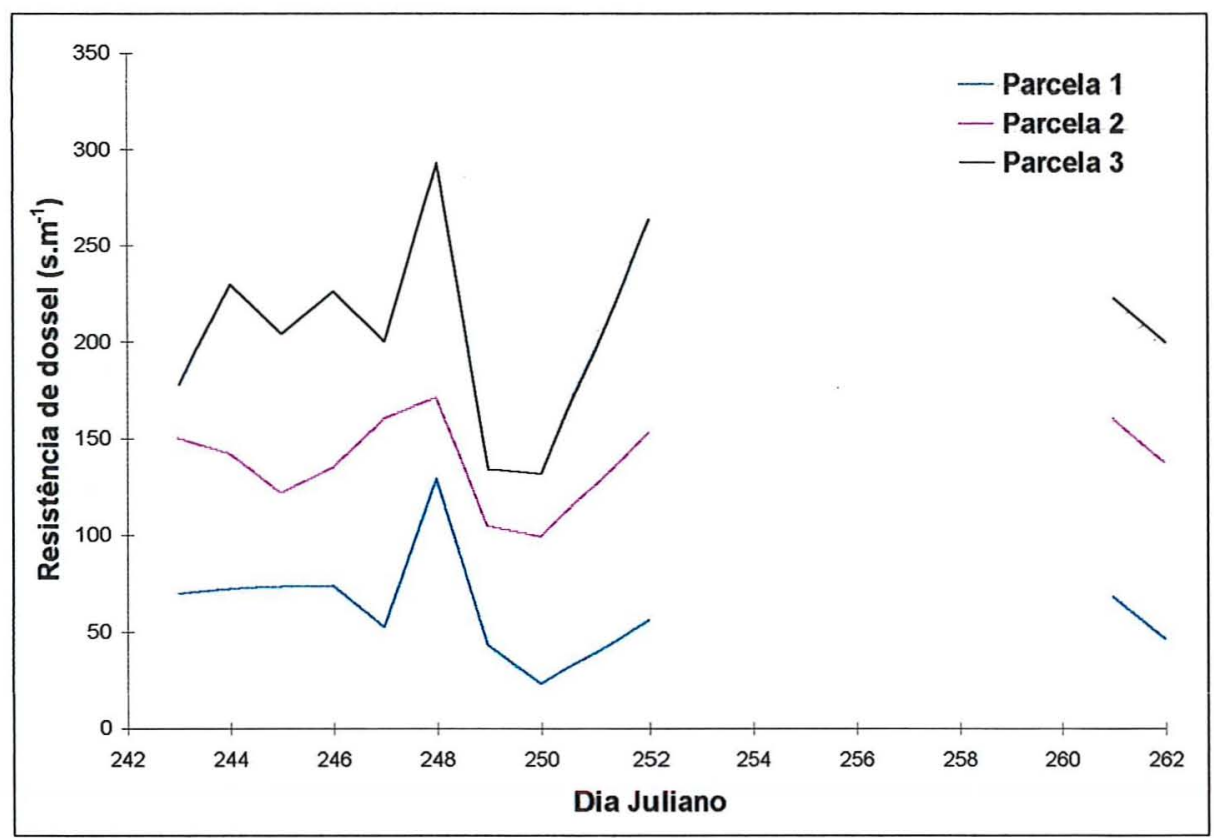

Figura 10. Variação da resistência do dossel da grama com o uso da termometria ao infravermelho nas parcelas 1,2 e 3 para períodos de luz.

\subsection{Evapotranspiração da cultura}

Na Tabela 9 e Figura 11, são apresentados os valores de evapotranspiração estimados pela equação de Penman-Monteith e medidos no lisímetro de pesagem, no período de 24 horas. Comparando-se os valores das três parcelas, verificou-se que os maiores valores estimados de ETo ocorreram na parcela 1, na qual a tensão da água do solo foi menor. Comparando-se os valores das parcelas 2 e 3 , verificou-se que os maiores valores estimados de ETo ocorreram na parcela 2, exceto nos dias 243 e 249. Como a diferença da radiação líquida e o fluxo de calor no solo apresentaram valores muito próximos entre as parcelas, a resistência de dossel foi determinante na ordem de grandeza dos valores de evapotranspiração. Os valores médios de ETo encontrados para as parcelas 1,2 e 3 foram de 4,37; 3,93 e 3,78 mm.dia ${ }^{-1}$, respectivamente.

$\mathrm{Na}$ Tabela 10 e Figura 12, são apresentados os valores de evapotranspiração estimados pela equação de Penman-Monteith e medidos no lisímetro de pesagem, para períodos de luz. Da mesma forma que para o período de 24 horas, constatou-se que, de modo geral, quanto menor for a tensão de água no solo, maior é o valor estimado da 
Tabela 9. Valores de evapotranspiração $\left(\mathrm{mm}^{\mathrm{d}} \mathrm{dia}^{-1}\right)$ determinados pelo lisímetro (ETo lisímetro) e estimados para as parcelas 1, 2 e 3 pela equação de PenmanMonteith (ETo PM) com o uso de termometria ao infravermelho, no período de 24 horas.

\begin{tabular}{ccccc}
\hline Dia Juliano & $\begin{array}{c}\text { ETo } \\
\text { Lisímetro }\end{array}$ & $\begin{array}{c}\text { ETo } \\
\text { PM(Parcela 1) }\end{array}$ & $\begin{array}{c}\text { ETo } \\
\text { PM(Parcela 2) }\end{array}$ & $\begin{array}{c}\text { ETo } \\
\text { PM(Parcela 3) }\end{array}$ \\
\hline 243 & 4,13 & 4,54 & 4,00 & 4,06 \\
244 & 3,88 & 4,57 & 4,15 & 3,96 \\
245 & 4,34 & 4,48 & 4,25 & 3,99 \\
246 & 3,61 & 4,42 & 4,09 & 3,78 \\
247 & 3,68 & 4,08 & 3,57 & 3,53 \\
248 & 2,52 & 2,42 & 2,38 & 2,12 \\
249 & 4,01 & 3,88 & 3,46 & 3,49 \\
250 & 4,23 & 5,08 & 4,70 & 4,69 \\
252 & 4,50 & 5,62 & 4,81 & 4,38 \\
261 & 4,03 & 4,44 & 3,89 & 3,74 \\
262 & 4,83 & 4,49 & 3,96 & 3,80 \\
\hline Média & $\mathbf{3 , 9 8}$ & $\mathbf{4 , 3 7}$ & $\mathbf{3 , 9 3}$ & $\mathbf{3 , 7 8}$ \\
\hline
\end{tabular}

Tabela 10. Valores de evapotranspiração $\left(\mathrm{mm}\right.$ dia $\left.^{-1}\right)$ determinados pelo lisímetro (ETo lisímetro) e estimados para as parcelas 1, 2 e 3 pela equação de PenmanMonteith (ETo PM) com o uso da termometria ao infravermelho, para periodo de luz.

\begin{tabular}{ccccc}
\hline Dia Juliano & $\begin{array}{c}\text { ETo } \\
\text { Lisímetro }\end{array}$ & $\begin{array}{c}\text { ETo } \\
\text { PM(Parcela 1) }\end{array}$ & $\begin{array}{c}\text { ETo } \\
\text { PM(Parcela 2) }\end{array}$ & $\begin{array}{c}\text { ETo } \\
\text { PM(Parcela 3) }\end{array}$ \\
\hline 243 & 3,33 & 4,09 & 3,53 & 3,41 \\
244 & 3,26 & 3,79 & 3,33 & 2,90 \\
245 & 3,68 & 4,12 & 3,79 & 3,35 \\
246 & 3,10 & 3,87 & 3,40 & 2,92 \\
247 & 3,27 & 3,79 & 3,20 & 3,10 \\
248 & 2,01 & 2,09 & 1,92 & 1,53 \\
249 & 3,27 & 4,03 & 3,52 & 3,40 \\
250 & 3,41 & 4,60 & 3,97 & 3,82 \\
252 & 3,49 & 5,05 & 4,06 & 3,36 \\
261 & 2,95 & 4,21 & 3,37 & 2,98 \\
262 & 4,14 & 4,34 & 3,67 & 3,35 \\
\hline Média & $\mathbf{3 , 2 6}$ & $\mathbf{4 , 0 0}$ & $\mathbf{3 , 4 0}$ & $\mathbf{3 , 1 0}$ \\
\hline
\end{tabular}




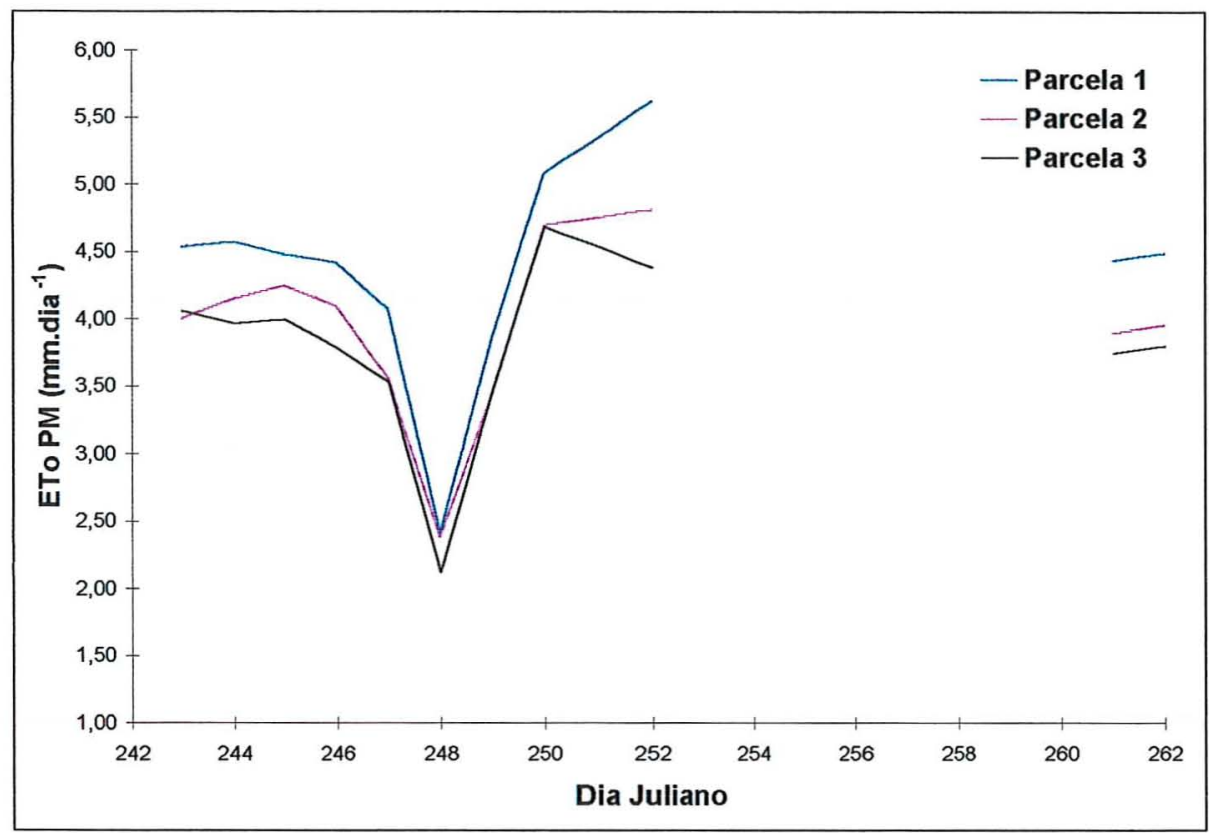

Figura 11. Evapotranspiração estimada pela equação de Penman-Monteith, utilizando valores de resistência de dossel com o uso da termometria ao infravermelho, no período de 24 horas.

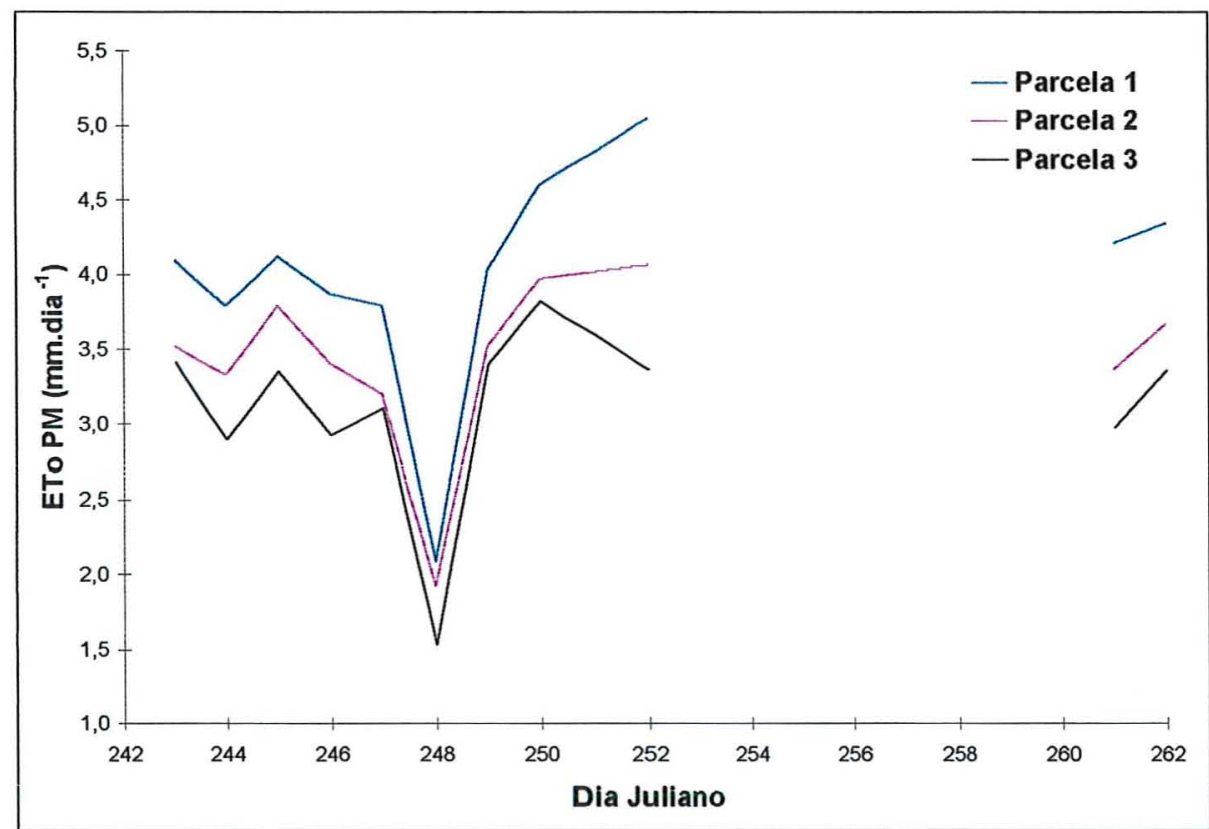

Figura 12. Evapotranspiração estimada pela equação de Penman-Monteith, utilizando valores de resistência de dossel com o uso da termometria ao infravermelho, no período de luz. 
ETo. Os valores médios de ETo estimados pela equação de Penman-Monteith durante o período foram de 4,0;3,4 e 3,1 mm.d $\mathrm{d}^{-1}$, para as parcelas 1, 2 e 3, respectivamente.

A estimativa da evapotranspiração de referência pela equação de PenmanMonteith na parcela 1, usando valores de resistência de dossel obtidos com o uso da termometria ao infravermelho, foi comparada com a evapotranspiração medida no lisimetro de pesagem, nos períodos de 24 horas e período de luz. Na Figura 13, é apresentada a relação dos valores de ETo medidos no lisímetro e estimados pela equação de Penman-Monteith no período de 24 horas. Verificou-se que em média, o valor estimado pela equação de Penman-Monteith superestimou em 24,8\% a ETo medidos em lisímetro de pesagem (Tabela 9). O coeficiente de determinação para o período de 24 horas foi 0,66 e o índice de concordância Id foi de 0,81 .

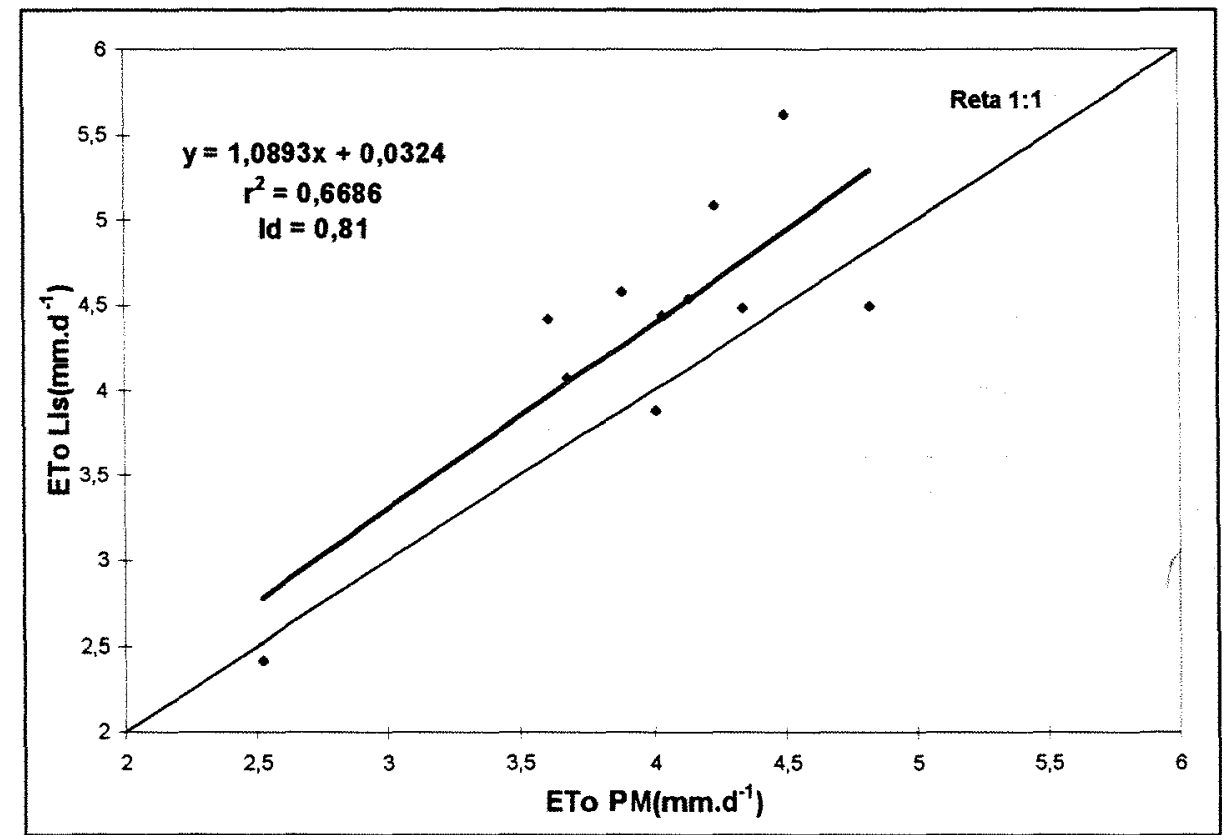

Figura 13. Evapotranspiração estimada pela equação de Penman-Monteith com o uso da termometria ao infravermelho em relação a evapotranspiração medida em lisímetro de pesagem para períodos de 24 horas.

No período de luz, (Figura 14), observou-se que os valores do coeficiente de determinação e do índice de concordância (Id), foram inferiores aos obtidos no período 
de 24 horas. De maneira semelhante ao ocorrido no periodo de 24 horas, o valor estimado pela equação de Penman-Monteith superestimou em média a ETo medida no lisímetro de pesagem em $22,7 \%$ (Tabela 10). Uma das possíveis causas das diferenças observadas entre os periodos de luz e de 24 horas, está associada a redução da atividade fisiológica da grama, aumentando assim a quantidade de folhas secas em relação às verdes. Este aumento da massa seca promoveu uma elevação da temperatura da superficie, que foi registrada pelos termômetros, refletindo em um maior valor de rc. Um outro componente que deve ser levado em consideração, é a advecção de calor sensível na área experimental, principalmente durante o período diurno onde verificou-se maiores elevações na temperatura do ar e menores valores de umidade relativa. No período de 24 horas, essa fonte de erro foi minimizada em função das menores flutuações observadas para as variáveis meteorológicas de temperatura e umidade relativa do ar, permitindo um melhor ajuste com a utilização do modelo de Penman-Monteith.

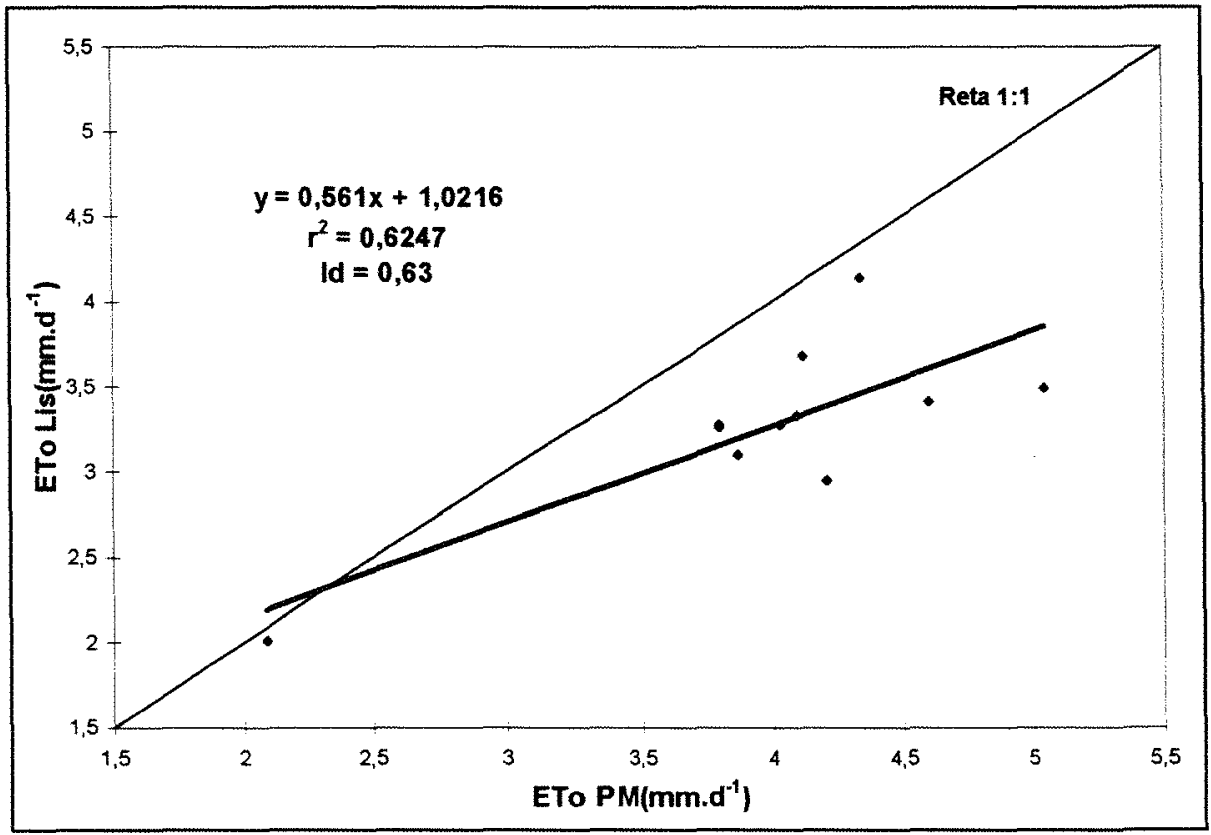

Figura 14. Evapotranspiração estimada pela equação de Penman-Monteith com o uso da termometria ao infravermelho em relação a evapotranspiração medida em lisímetro de pesagem para períodos de luz. 


\subsection{Diferenças entre a temperatura do dossel da cultura e do ar (Tc-Ta)}

Na Figura 15 encontram-se apresentados os valores das diferenças de temperatura do dossel da cultura e do ar (Tc-Ta) em períodos de 24 horas durante os dias estudados. Observou-se que para a maioria dos dias estudados, a parcela com menor tensão de água no solo (parcela 1) apresentou valores negativos de (Tc-Ta), devido a maior transpiração da cultura proporcionada pela maior disponibilidade de água no solo. A mesma tendência não é observada nas parcelas 2 e 3, onde a disponibilidade de água é menor. De maneira geral, pode-se observar que existe uma relação direta entre a tensão de água no solo e os valores de (Tc-Ta), ou seja, tomando por base a parcela mais bem suprida de água, a diferença média entre $\left(\mathrm{Tc}-\mathrm{Ta}\right.$ ) foram de $1,5^{\circ} \mathrm{C}$ na parcela 2 e $1,8^{\circ} \mathrm{C}$ na parcela 3 .

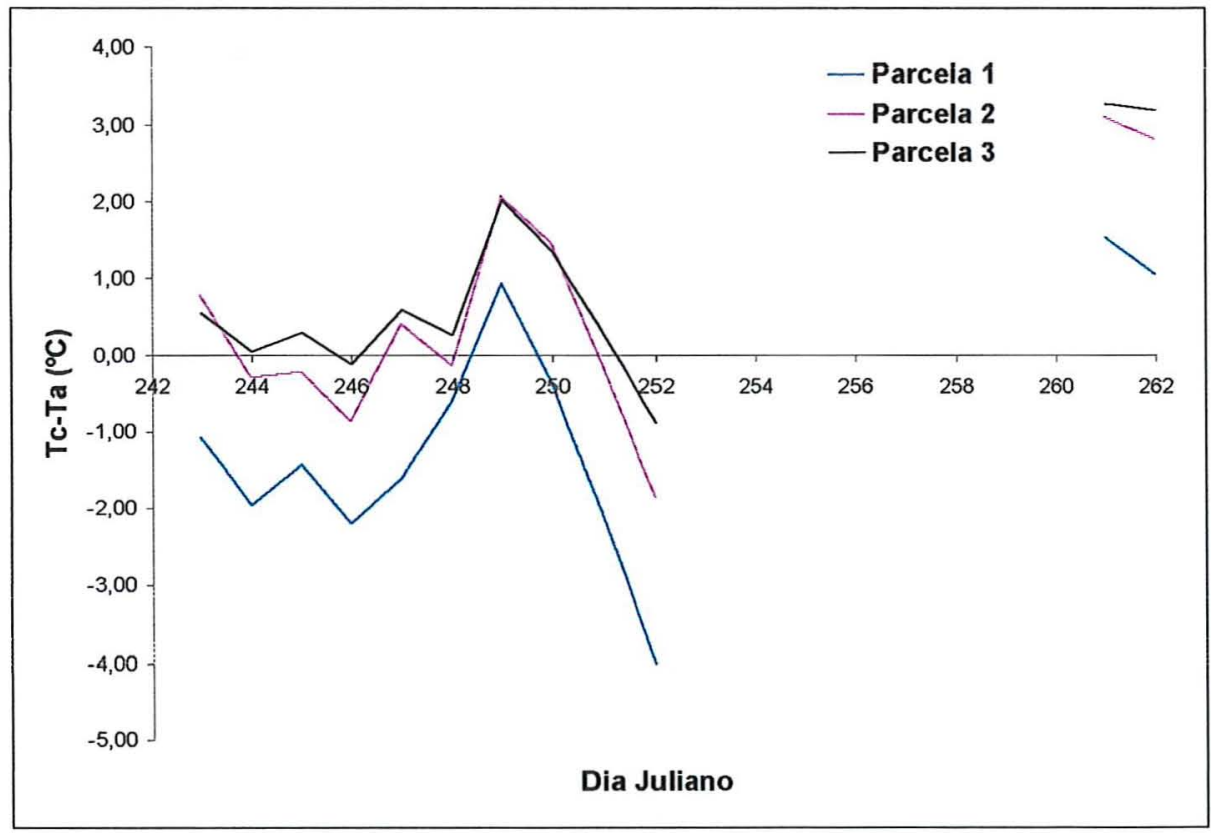

Figura 15. Diferença de temperatura do dossel da grama e do ar para os dias estudados em períodos de 24 horas.

Na Figura 16 estão representados as diferenças de temperatura do dossel da grama e do ar para períodos de luz. Observa-se que na maioria dos casos a diferença entre os valores médios de Tc-Ta é positiva, pois a temperatura da cobertura do dossel é 
superior a do ar, principalmente nos horários de maior radiação líquida. As diferenças médias entre (Tc-Ta) em comparação com a parcela 1 foram maiores neste período, com valores de $2,8^{\circ} \mathrm{C}$ na parcela 2 e $4,7^{\circ} \mathrm{C}$ na parcela 3 .

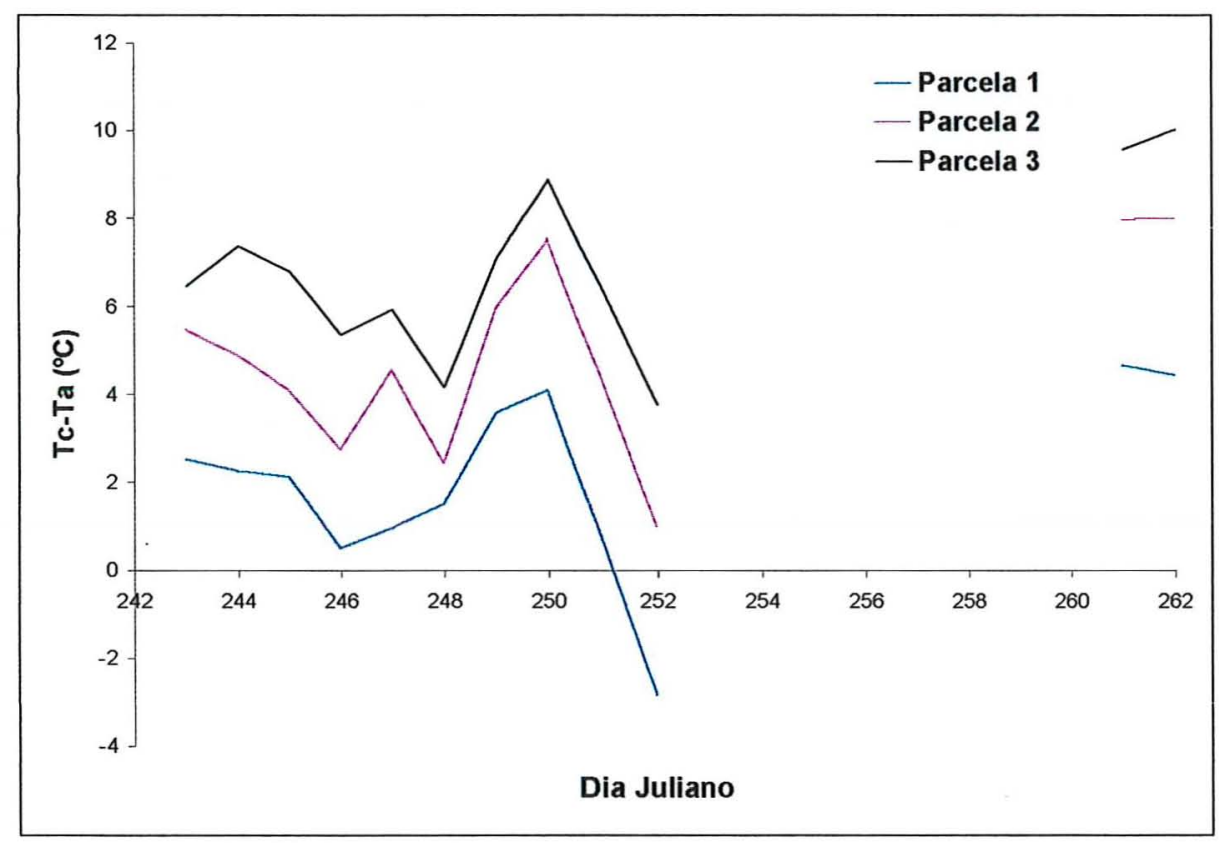

Figura 16. Diferença de temperatura do dossel da grama e do ar para os dias estudados em períodos de luz.

Na Figura 17 observou-se as variações horárias de Tc-Ta, radiação líquida e temperatura do ar para quatro dias selecionados no período estudado. Verificou-se que as diferenças entre Tc-Ta foram negativas nas primeiras horas da manhã e no final da tarde. Este fato pode estar relacionado a pequena radiação líquida nesta hora do dia, o que reflete em uma pequena temperatura do dossel, que por sua vez é menor que a temperatura do ar, tornando a diferença (Tc-Ta) negativa. No decorrer do dia, o aumento da radiação associado ao aumento da temperatura do ar promovem uma elevação da temperatura do dossel, sendo este aumento proporcionalmente maior na temperatura da cobertura do dossel, tornando a diferença (Tc-Ta) positiva. 


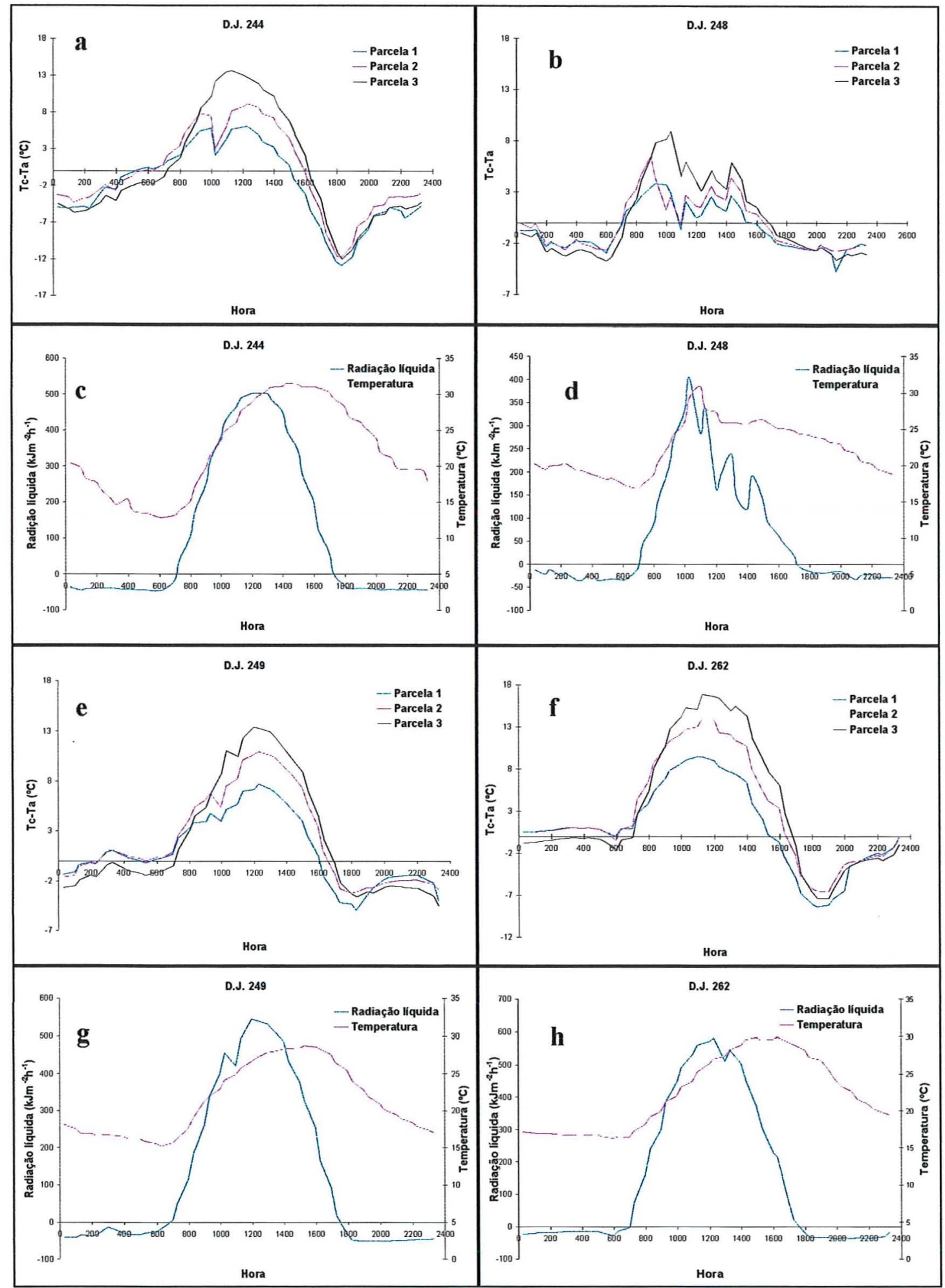

Figura 17. Variação de (Tc-Ta), radiação líquida $(\mathrm{Rn})$ e temperatura do ar para os dias 244 (a, c). 248 (b, d). 249 (e, g) e 262 (f, h). 
A análise da Figura 17 permite verificar o efeito direto dos valores de radiação e temperatura do ar na diferença (Tc-Ta). No inicio da manhã, as diferenças (Tc-Ta) foram próximas para as Parcelas 1 e 2, e estas diferenças tornaram-se positivas primeiro nestas parcelas. O efeito da pequena radiação associada às temperaturas mais baixas nestas horas da manhã, podem estar relacionadas ao fato de não se Ter sido observada a relação direta entre a tensão da água no solo e a diferença (Tc-Ta). No final da tarde, a diferença (Tc-Ta) tornou-se negativa primeiro na parcela 1 e posteriormente nas parcelas 2 e 3 . Isto pode estar relacionado ao efeito da tensão da água no solo na diferença (Tc-Ta), ou seja, quanto menor o estresse, menor é o valor da temperatura do dossel, o que levou a diferença de temperatura ( $\mathrm{Tc}-\mathrm{Ta}$ ) negativa a ocorrer primeiro na parcela com menor estresse (Figuras 15 e 16).

No dia 248 , (Figura 17, b, d) foram observados as maiores variações (Tc-Ta) no decorrer do dia, pois neste dia ocorreu uma maior variação da radiação líquida, o que provavelmente foi um dia nublado. A ocorrência destes dias são fontes de erro quando se pretende usar índices baseados na temperatura da cobertura conforme descrito por Folegatti (1988). Verificou-se também a diminuição da diferença (Tc-Ta) durante o período das 10:00 às 12:00 horas nas parcelas 1 e 2 por resfriamento da folha, decorrente da aplicação de uma lâmina de água para manutenção da umidade do solo.

Vale destacar que os resultados obtidos na trabalho são válidos para o período estudado, pois além dos efeitos das variáveis meteorológicas, o estádio fenológico da cultura influenciou nas medidas da temperatura, o que pode levar a resultados diferentes para outras épocas do ano. 


\section{CONCLUSÕES}

A partir dos resultados obtidos e analisados neste trabalho, concluiu-se que:

$\mathrm{O}$ valor médio da resistência de dossel (rc) determinado como resíduo, em periodos de 24 horas foi muito próximo ao valor parametrizado por Smith (1991). No período de luz determinou-se um valor maior de rc.

$\mathrm{O}$ índice de área foliar (IAF) determinado foi inferior ao parametrizado para cultura de referência.

Os valores médios de rc estimados pela termometria ao infravermelho aumentaram com o aumento da tensão de água no solo, tanto nos periodos de 24 horas como nos período de luz.

Para uma mesma Parcela, o valor médio de rc estimados pela termometria ao infravermelho foi maior para o período de luz em relação ao período de 24 horas

Para os períodos de 24 horas e de luz, os valores médios da evapotranspiração estimados pela equação de Penman-Monteith, com o uso da termometria ao infravermelho suplantaram os valores médios da ETo determinados no lisímetro. Ocorreu um decréscimo da ETo estimada com o aumento da tensão de água no solo.

De maneira geral, verificou-se a existência de uma relação direta entre a tensão de água no solo e os valores de (Tc-Ta). 


\section{REFERÊNCIAS BIBLIOGRÁFICAS}

ABOUKHALED, A.; ALFARO, A.; SMITH, M. Lysimeters. Rome: FAO, 1982. 68p. (FAO. Irrigation and Drainage Paper, 39)

ALLEN, R. G. A Penman for all seasons. Journal and Irrigation and Drainage Engineering, v.112, n.4, p.348-368, 1986.

ALLEN, R. G.; PRUEGER, J. R.; HILL, R. W. Evapotranspiration from isolated stands of hydrophytes: cattail and bulrush. Transactions of the ASAE, v.35, n.4, p.1191$1198,1992$.

ALLEN, R. G.; JENSEN, M. E.; WRIGHT, J. L.; BURMAN, R. D. Operational estimates of references evapotranspiration. Agronomy Journal, v.81, n.4, p.650-62, July/Aug. 1989.

BEN-ASHER, J.; MEEK, D. W.; HUTMACHER, R. B.; PHENE, C. J. Computational approach to assess actual transpiration form aerodynamic and canopy resistance. Agronomy Journal, v.81, n.5, p.776-782, 1989.

BERKOWICZ, R.; PRAHM, L. P. Sensible heart flux estimated from routine meteorological data by resistance method. Journal of Applied Meteorology, v.21, p. $1845-1864,1982$. 
BERLINER, P.; OOSTERHUIS, D. M.; GREEN, G. C. Evaluation of the infrared thermometer as a crop stress detector. Agricultural and Forestry Meteorology, v.31, p.219-230, 1984.

BRUIN, H. A. R.; HOLTSLAG, A. A. M. A simple parameterization of the surface fluxes of sensible and latent heat during daytime with the Penman-Monteith concept. Journal of Applied Meteorology, v.21, p. 1610-1621, 1982.

BRUTSAERT, W. Evaporation into the atmosphere: theory, history and applications. Dordrecht, Kluver Academic, 1982. 299p. (Environmental Fluid Mechanics, 1)

COSTA, A. B. F. Uso da termometria ao infravermelho para caracterizar a necessidade de irrigação do feijoeiro (Phaseolus vulgaris, L.). São Paulo, 1995 69p. Dissertação (Mestrado) - Instituto Astronômico e Geofísico, Universidade de São Paulo.

DENMEAD, O. T., SHAW, R. H. Availlability of soil Water to plants as affected by soil moisture content and metorological conditions. Agronomy Journal, 45: 385$390,1962$.

DOORENBOS, J.; KASSAM, A. H. Yield response to water. Rome: FAO, 1979. 179p. (FAO. Irrigation and Drainage Paper, 33).

DOORENBOS, J.; PRUITT, W. O. Guidelines for predicting crop water requeriments. Rome: FAO, 1975. 179p. (FAO. Irrigation and Drainage Paper, 24).

EPIPHANIO, J. C. N.; CARVALHO, L. J. C. B.; VITORELLO, I.; VALÉRIO FILHO, M. Sensoriamento remoto termal na discriminação de cultivares de soja submetidas a estresse hídrico. Pesquisa Agropecuária Brasileira, v.24, n.2, p.253-258, 1989. 
FOLEGATTI, M. V. Avaliação do desempenho de um "scheduler" na deteç̧ão do estresse hídrico em cultura do feijoeiro (Phaseolus vulgaris, L) irrigada com diferentes lâminas. Piracicaba, 1988. 188p. Tese (Doutorado) - Escola Superior de Agricultura "Luiz de Queiroz", Universidade de São Paulo.

GRANT, D. R. Comparation of evaporation from barley with Penmam estimates. Agricultural Meteorology, v.15, p.49-60, 1975.

HATFIELD, J. L. Reserts priorities in ET: evolving methods. Transactions of the ASAE, v.31, n.2, p.491-495, Mar./Apr. 1988.

IDSO, S. B.; JACKSON, R. D.; REGINATO, R. J. Remote sensing of crops yields. Science, v.196, p.19-25, 1977.

IDSO, S. B.; JACKSON, R. D.; EHLER, W. L. et al. A method for determination of infrared emitance of leaves. Ecology, v.50, n.5, p.899-902, 1969.

JACKSON, R. D.; IDSO, D. B.; REGINATO, R. J.; PINTER Jr., P. J. Canopy temperature as crop water stress indicator. Water Resources. Research., v.17, n. 4, p. 1133-1138, 1981.

JENSEN, M. E. Consumptive use of water and irrigation water requeriments. New York: ASCE, 1973. 215p.

JOHNS, D.; BEARD, J. B.; van BAVEL, C. H. M. Resistances to evapotranspiration from St. Augustinegrass turf canopy. Agronomy Journal. Madison. V. 75, n 3, p. 419-422, 1983. 
KALMA, J. D.; JUPP, D. L. B. Estimating evaporation from pasture using infrared thermometry: evaluation of a one layer resistance model. Agricultural and Forestry Meteorology, v.51, p.223-246, 1990.

KHERA, K. L.; SANDHU, B. S. Canopy temperature of sugarcane as influenced by irrigation regime. Agricultural and Forestry Meteorology, v.37, p.245-258, 1986.

KOBAYASHI, M. K. Determinação do índice de estresse hídrico da cultura do feijoeiro (Phaseolus vulgaris, L.) por meio da termometria a infravermelho, e fator de disponibilidade de água no solo, em minilisímetro de pesagem.Viçosa, 1996. 70p. Dissertação (Mestrado) - Universidade Federal de Viçosa.

KROON, L. J. M.; BRUIN, H. A. R. Atmosphere-vegetation interaction in local advection condition: efect of lower boundary conditions. Agricultural and Forestry Meteorology, v.64, p.1-28, 1993.

LHOME, J. P. The concept of canopy resistance: historical survey and comparison of different approaches. Agric. Forest Meteor., Amsterdam, v. 54, p. 227-240, 1991.

MAGIOTTO, S. R. Estimativa da evapotranspiração de referência pelo uso da termometria ao infravermelho. Piracicaba, 1996, 90p. Dissertação (Mestrado) Escola Superior de Agricultura "Luiz de Queiroz", Universidade de São Paulo.

MONTEITH, J. L. Evaporation and environment. Symposium Society Experimental Biology of London, v. 19, p.205-234, 1965.

MONTEITH, J. L. Principles of environmental physics. New York: American Elsevier Pub., Inc., 1973. 241 p. 
MONTEITH, J. L. Evaporation and surface temperature. Quartely Journal Royal Meteorological Society, v.107, n.451, p.1-27, 1981.

MONTEITH, J. L. Evaporation fron lands surfaces: progress in analysis and predictionsice 1948. In: NATIONAL CONFERENCE ON ADVANCES IN EVAPOTRANSPIRATION, Chicago, 1985. Proceedings. St. Joseph: ASAE, 1985. p.4-12.

MONTEITH, J. L.; SZEICZ, G. Radiative temperature in the heat balance of natural surfaces. Quartely Journal of Royal Meteorological Society, v.88, p.496-507, 1962.

O'TOOLE, J. C.; REAL, J. G. Estimation of aerodynamic and crop resistence from canopy temperature. Agronomy Journal, v.78, n.2, p.305-310, Mar./Apr., 1986.

OKE, T. R. Boundary layer climates. 2.ed. London: Routlegde, 1992. 435p.

PENMAN, H. L. Natural evaporation fron open water, bare soil and grass. Proceedings of the Royal Society of London, v. 198, p.116-140, 1948.

PEREIRA, A. R.; VILLA NOVA, N. A.; SEDIYAMA, G. C. Evapo(transpi)ração. Piracicaba: FEALQ. 1997. 183p.

PERES, J. G. Avaliação do modelo de Penman-Monteith, padrão FAO, para estimar a evapotranspiração de referência nas condições climáticas do estado de São Paulo. Piracicaba, 1994. 115p. Tese (Doutorado)-Escola Superior de Agricultura "Luíz de Queiroz", Universidade de São Paulo.

RUSSEL, G. Crop evapotranspiration, surface resistance and soil water status. Agricultural Meteorology, v.21, n. 3/4, p.213-226, Dec. 1980. 
SEDIYAMA, G. C. Estimativa da evapotranspiração: histórico, evolução e análise crítica. Revista Brasileira de Agrometeorologia, v.4, n.1, p.i-xii, 1996.

SHARMA, M. L. Estimating evapotranspiration. In: HILLEL, D. Advances in irrigation. New York: Academic Press, 1983. v.3, p. 213-281.

SILVA, F. C. Uso de dispositivos lisimétricos para medida da evapotranspiração de referência. Piracicaba, 1996, 73 p. Dissertação (Mestrado). Escola Superior de Agricultura "Luíz de Queiroz", Universidade de São Paulo.

SMITH, M., Ed. Report on the expert consultation on produceres for revision of FAO guidelines for prediction of crop water requeriments. Rome: FAO, 1991. $45 \mathrm{p}$.

THON, A. S. Momentum, mass and heat exchange pf plant communities. In: MONTEITH, J. L., ed. Vegetation and the atmosphere. Londom, AcademicPress, 1975. v. 1 , chap. 3 , p. 57-109.

THORNTWAITE, C. W. An approach toward a rational classification of climate. Geographical Review. New York, v.38, p.55-94, 1948.

VILLA NOVA, N. A; REICHARDT, K. Evaporação/Evapo(transpi)ração de um ecossistema e suas relações com o meio ambiente. Engenharia Hidrológica, v.2, p. $145-197,1989$.

WALKER, G. K. Evaporation from wet soil surface beneat plant canopies. Agricultural and Forestry Meteorology, v.33, p.259-264, 1984.

WIEGAND, C. L.; NANKEN, L. N. Influences of plants moisture stress, solar radiation and temperature. Agronomy Journal, v.58, p.552-556, 1966. 
WILLMOTT, C. J. On the validation of models. Physical Geography, v. 2, p. 184-194, 1981. 